\title{
Drudgery reduction, physical activity and energy requirements in rural livelihoods
}

\section{Article}

\section{Accepted Version}

Creative Commons: Attribution-Noncommercial-No Derivative Works 4.0

Srinivasan, C. S., Zanello, G. ORCID: https://orcid.org/00000002-0477-1385, Nkegbe, P., Cherukuri, R., Picchioni, F., Gowdru, N. and Webb, P. (2020) Drudgery reduction, physical activity and energy requirements in rural livelihoods. Economics and Human Biology, 37. 100846. ISSN 1570-677X doi: https://doi.org/10.1016/j.ehb.2019.100846 Available at https://centaur.reading.ac.uk/88344/

It is advisable to refer to the publisher's version if you intend to cite from the work. See Guidance on citing.

Published version at: https://www.sciencedirect.com/science/article/pii/S1570677X19301571?via\%3Dihub

To link to this article DOI: http://dx.doi.org/10.1016/j.ehb.2019.100846

Publisher: Elsevier

All outputs in CentAUR are protected by Intellectual Property Rights law, including copyright law. Copyright and IPR is retained by the creators or other copyright holders. Terms and conditions for use of this material are defined in the End User Agreement.

\section{www.reading.ac.uk/centaur}

\section{CentAUR}


Central Archive at the University of Reading

Reading's research outputs online 


\section{Journal Pre-proof}

Drudgery Reduction, Physical Activity and Energy Requirements in Rural Livelihoods

C.S. Srinivasan (Conceptualization) (Methodology) (Formal analysis) (Writing - original draft) (Writing - review and editing),

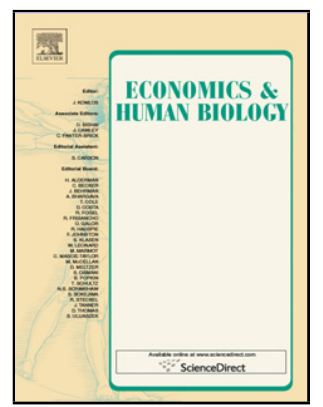
Giacomo Zanello (Supervision) (Project administration) (Investigation) (Conceptualization) (Methodology) (Software) (Formal analysis) (Writing - original draft) (Writing - review and editing), Paul Nkegbe (Project administration) (Investigation) (Data curation) (Writing - review and editing), Radhika Cherukuri (Project administration) (Investigation) (Data curation) (Writing - review and editing), Fiorella Picchioni (Investigation) (Data curation) (Formal analysis) (Software)<ce:contributor-role $>$ Visualisation), Nithya Gowdru (Investigation) (Data curation) (Writing - review and editing), Patrick Webb<ce:contributor-role>Conceptualisation) (Writing - review and editing)

PII: S1570-677X(19)30157-1

DOI: https://doi.org/10.1016/j.ehb.2019.100846

Reference: EHB 100846

To appear in: Economics and Human Biology

Received Date: 24 May 2019

Revised Date: 17 November 2019

Accepted Date: 27 December 2019

Please cite this article as: Srinivasan CS, Zanello G, Nkegbe P, Cherukuri R, Picchioni F, Gowdru N, Webb P, Drudgery Reduction, Physical Activity and Energy Requirements in Rural Livelihoods, Economics and Human Biology (2019), doi: https://doi.org/10.1016/j.ehb.2019.100846 
This is a PDF file of an article that has undergone enhancements after acceptance, such as the addition of a cover page and metadata, and formatting for readability, but it is not yet the definitive version of record. This version will undergo additional copyediting, typesetting and review before it is published in its final form, but we are providing this version to give early visibility of the article. Please note that, during the production process, errors may be discovered which could affect the content, and all legal disclaimers that apply to the journal pertain.

(C) 2019 Published by Elsevier. 


\section{Drudgery Reduction, Physical Activity and Energy Requirements in Rural Livelihoods}

C.S. Srinivasanª ${ }^{*}$ Giacomo Zanelloa, Paul Nkegbeb, Radhika Cherukuric, Fiorella Picchionia, Nithya Gowdruc, Patrick Webbd

a School of Agriculture, Policy and Development, University of Reading, UK

${ }^{b}$ Faculty of Integrated Development Studies, University for Development Studies, Ghana

c Centre for Agrarian Studies, National Institute of Rural Development and Panchayati Raj, India.

${ }^{d}$ Friedman School of Nutrition Science and Policy, Tufts University, USA

* Corresponding author. Email: c.s.srinivasan@reading.ac.uk

Highlights

- Physical activity and energy expenditure are important determinants of nutritional status.

- Very limited empirical evidence on energy expenditure patterns in rural livelihoods.

- We use innovative technology to generate robust energy expenditure data.

- We show that drudgery reduction can significantly improve nutritional status

- Energy expenditure may be important missing link in agriculture-nutrition pathways

- Effects of drudgery reduction vary by gender and socio-demographic characteristics.

- Nutrition interventions must explicitly consider the energy expenditure dimension.

\section{Abstract}

Low- and middle-income countries in Asia and Africa have been witnessing a process of rural transformation, characterised by rising agricultural productivity, commercialisation of agriculture, improved infrastructure and access to services, over several decades. However, there is little empirical evidence on how this transformation process has affected the patterns and intensity of physical activity and time use in rural livelihoods. The lack of empirical evidence can be attributed to the constraints in accurate measurement of physical activity and energy expenditure in the context of free-living populations. Using wearable accelerometry devices, we develop robust energy expenditure profiles for men and women in rural households for two case studies in India and Ghana. An innovative feature of this study is the integration of data on energy expenditure (derived from accelerometers) with data on time-use, which has hitherto not been feasible in observational studies of rural populations. Using the data on physical activity, energy expenditure and time use from the case studies, we examine the impact of drudgery reduction- the substitution of less intense for more intense activities - on energy requirements for men and women in rural households. Our results show that drudgery reduction can have large effects on human energy 
(calorie) requirements, with an hour of drudgery reduction reducing energy requirements by 11$22 \%$ for men and 13-17\% for women in Ghana and India. There are significant gender differences in energy expenditure patterns and drudgery reduction effects vary by socio-demographic characteristics and endowments of households. Our results suggest that drudgery reduction can offer rural households an important route to improved nutritional status. At the same time, drudgery reduction can lead to increased incidence of overweight and obesity for some segments of the population. The design of development interventions needs to explicitly consider the effects on nutrition and well-being through the energy expenditure dimension.

Keywords: Physical activity; energy expenditure; accelerometry; nutritional status; agricultural development; rural livelihoods.

Classification codes: I12, Q12, 013 


\section{Introduction}

Most low- and middle-income countries (LMICs) in Asia and Africa have been undergoing a process of rural transformation over several decades (Webb and Block, 2012). This process involves rising agricultural productivity through the adoption of modern technology, diversification of crop production patterns and commercialisation of agriculture. It also involves diversification of rural livelihoods, through off-farm employment and improvements in public health, transport and communication infrastructure and access to services in rural areas (IFAD, 2016). The rural transformation process can be expected to induce substantial changes in the patterns of physical activity, energy expenditure and time-use associated with rural livelihoods. Understanding the nature of these changes is important for the design of interventions aimed at improving the nutrition, health and well-being of rural inhabitants (Johnston et al., 2018) However, reliable empirical evidence on the patterns of physical activity, energy expenditure and time use in rural livelihoods in LMICs has been limited on account of the constraints in accurate measurement of these parameters, particularly energy expenditure, in free living populations. This paper addresses this gap by taking advantage of emerging consumer friendly wearable technologies for physical activity monitoring. Integrating data from wearable accelerometers with household survey data, we generate robust activity, energy expenditure and time-use profiles for rural agricultural households in an LMICs context.

Robust livelihood energy expenditure profiles can provide significant inputs for policy or programme interventions aimed at improving rural welfare. Physical activity and energy expenditure profiles can contribute more accurate assessments of the incidence, depth and severity of undernutrition and poverty (in cases where undernutrition levels are defined in relation to average reference calorie requirements as is the case in the assessments of global hunger and food insecurity made by the FAO and IFPRI (FAO, 2015; von Grebmer et al., 2015) in low and middle income countries). Although recent initiatives have highlighted the need for better data to monitor food systems and nutrition outcomes (Global Panel, 2015; IFPRI, 2015), 
the assessment of the incidence of undernutrition/poverty is still often based on expenditure/consumption/dietary surveys using normative energy requirement figures (which may vary by age group or gender). The variation in energy requirements across sociodemographic and occupational/livelihood categories and agro-climatic zones is not taken into account in the assessment of undernutrition - a factor which may significantly bias the assessment of calorie deficits in the population at risk of undernutrition. Knowledge of energy expenditure profiles can provide a better understanding of the influence of livelihood strategies and activities, environmental factors (e.g., climate and temperature) and access to health and physical infrastructure on energy expenditure patterns and inform better targeting of nutrition interventions.

Examination of energy expenditure profiles can provide a better understanding of the link between productivity-enhancing interventions and nutrition outcomes for individuals within a household. In many developing countries, there appears to be a perplexing disconnect between agricultural productivity growth and expected improvements in nutrition status (Gillespie and Kadiyala, 2012; Meeker and Haddad, 2013; Fan et al., 2019). Productivity-enhancing agricultural and food processing interventions impact nutrition and health outcomes in rural livelihoods through complex pathways that have yet to be well documented (Headey et al., 2011; Dangour, 2013). Delineation of the linkages between productivity enhancement and improvements in nutrition has been a major concern to policy makers and has been the subject of considerable recent research (Turner et al., 2013). The changes in the physical activity, energy expenditure and time-use patterns associated with productivity-enhancing interventions can be expected to have an important influence on the nutrition status of the rural population. However, empirical studies on nutrition impacts have tended to focus only on the quantum and distribution of gains in consumption following interventions while the energy expenditure dimension has been neglected.

This paper generates robust energy expenditure profiles to examine how changes in physical activity patterns, particularly drudgery reduction (DR), can affect the energy requirements of 
men and women in rural households in LMICs and the implications that this may have for their nutritional status (calorie adequacy). We address the following research questions:

(1) What are the patterns of energy expenditure and time-use for activities in rural livelihoods?

(2) How do energy requirements differ by gender?

(3) How much energy could be saved through DR? How does the potential for reduction in energy expenditure through DR vary by household characteristics and endowments?

Our analysis based on data from two case studies of rural households in Ghana and India suggests that in the context of rural livelihoods in LMICs, DR can offer substantial savings in energy expenditure that could offset the calorie deficits faced by some segments of the population. DR could offer an important and substantial route to nutritional improvement in rural livelihoods. At the same time DR can also lead to increasing incidence of overweight and obesity in rural areas. The energy expenditure dimension associated with changing patterns of activity in rural livelihoods may be an important factor explaining agriculture-nutrition linkages.

Section 2 explains the concept of DR employed in this paper and the factors influencing the potential for DR in the context of rural livelihoods. Section 3 examines the previous literature on physical activity patterns in rural livelihoods and the link to agriculture-nutrition linkages. Section 4 describes the data and methods used in the paper. Section 5 presents the results which are discussed in Section 6 and Section 7 concludes.

\section{Explaining drudgery reduction in rural livelihoods}

We define DR as the substitution of activities with moderate/vigorous/very vigorous energy intensity with activities of light energy intensity. We conceptualise the drudgery faced by men and women in rural households as being determined by the compulsions of subsistence, opportunities/capacity for productive work and socio-cultural norms influencing the allocation of physical activities between members of a household (e.g., ploughing may be undertaken by 
men while transplanting of paddy may be done by women). The potential for DR (and consequent reductions in energy requirements) will depend on the activities contributing to drudgery, their energy intensity and the avenues for substitution with activities of lesser energy intensity. The avenues for substitution of drudgery causing activities will in turn depend on the availability of, and access to, technologies for DR, household characteristics and endowments and the relevance of these avenues for different household members. For example, if ploughing using draught animals is a source of drudgery for men in agricultural households, the potential for DR may depend on the availability of mechanised ploughing using tractors, the household's ability to afford tractor services and skills to use tractors. Mechanisation of ploughing may, however, have no DR implications for women if they are not involved in the activity at all.

In specific rural contexts we expect that the avenues for drudgery reduction and the effects of drudgery reduction on energy requirements of individuals will vary with household characteristics and endowments. We expect the patterns physical activity and energy expenditure and the potential for DR to be different between the following categories of households:

Irrigated versus non-irrigated households: Households with irrigation facility are likely to undertake multiple cropping and are also more likely to adopt modern agricultural technology and practices. Availability of irrigation may also be an indicator of agricultural mechanisation. These differences suggest that patterns of physical activity in irrigated households are likely to different from non-irrigated households.

Small landholding versus large landholding households: Small landholding households are likely to be more reliant on family labour and have less potential for agricultural mechanisation (which may depend on the size of agricultural plots). Small landholding households may have a more diversified range of livelihoods and may be less reliant on agriculture. Larger landholding households may have greater possibilities/need for hiring labour and greater potential for mechanisation. Larger landholding may also be associated with better asset endowment. Thus, 
small and large landholding households may differ in terms of the physical activity demands from agricultural activities and in terms of the avenues of drudgery reduction open to them.

Wealthier versus less wealthy households: Wealthier households may possess more assets that can reduce drudgery (in agricultural or domestic activities) or they may have better access to credit to access these assets. They may also have better access to water and fuel supply and better modes of transportation. These differences in relation to less wealthy households may bring about differences in the patterns of physical activities and the choices available for drudgery reduction.

High dependency ratio versus low dependency ratio households: The differences in patterns of physical activity and avenues for drudgery reduction between high dependency and low dependency households are likely to arise because of the larger burden of caring for children and dependent adults in high dependency households, particularly for women. However, economically active women in high dependency households may be able to share childcare with other dependent adults in the household.

DR can affect nutritional status, specifically calorie adequacy - through a reduction in energy requirements. However, improvements in nutritional status can also affect physical activity levels by enhancing capacity for expending physical effort. The focus of this paper is on exogenous sources of DR such as adoption of new agricultural technology and mechanisation, improvements in rural infrastructure and services. Therefore, we do not examine the feedback effects of improved nutrition on physical activity levels.

\section{Literature review}

Empirical evidence on physical activity and energy expenditure patterns in rural households in LMICs has been limited. This is attributable to the difficulties in accurate measurement of physical activity and energy expenditures in free living populations. The "gold standard" method of 
measuring energy expenditure - the Doubly Labelled Water method (DLW)(Speakman, 1998) and direct and indirect calorimetry-based methods are all lab-based methods which are difficult to scale up for application to rural free-living populations. A review by Dufour and Piperata (2008) could identify only 26 studies reporting physical activity levels (PAL) of rural populations in low-income countries. PAL provides a more suitable measure of physical effort compared to total energy expenditure (TEE) because it corrects for body size, allowing comparison across gender and body-types. Most of these studies have used the so-called factorial method, which infers the total energy expenditure of an individual based on activity and time-use diaries. The time spent on each activity is multiplied by the average energy intensity of the activity derived from databases on normative energy requirements for different types of physical activity such as that provided by the FAO (2001) or estimated by indirect calorimetry methods (Durnin and Brockway, 1959). Other studies have used the DLW method and heart rate monitors (HRM) which provide energy expenditure estimates with accuracy within 3-5\% and $6 \%$ respectively of direct calorimetry estimates (Ceesay et al., 1989; Norgan, 1996). Vaz et al. (2005) compiled an extensive database of energy costs of specified activities, some of which are typical of rural populations in low-income contexts. Energy expenditure estimates for different activities derived using the factorial method show a huge variation by crops, location and technologies. Such estimates are useful to compare the relative energy cost and physical effort required for different activities. However, they generally do not take into account periods of rest and inactivity and variations in the intensity of the effort during the performance of an activity and, therefore, are likely to overestimate energy expenditure.

A review of empirical studies shows an average PAL of males and females in agricultural settings of 1.9 and 1.7 respectively, which is at the high end of what is considered to be "moderate" activity level (FAO, 2001). However, significant variations have been found across geographical locations and seasons. Studies of male farmers in Burkina Faso (Bleiberg et al., 1981), Cameroon (Pasquet and Koppert, 1993), and India (Edmundson and Edmundson, 1989) show light activity level (1.4>PAL $>1.69$ ), while vigorous activity levels (PAL $>2$ ) were found in Philippines (Guzman et al., 
1974), Gambia (Heini et al., 1996), and Thailand (Murayama and Ohtsuka, 1999). For females, vigorous activity levels were found only in Bangladesh amongst tea pickers (Vinoy et al., 2000). A few studies have collected data across different agricultural seasons revealing the diversity of physical activity levels across seasons. Greater differences across seasons were found in environments with a strong wet-dry seasonality where people rely on harvest of cereals for their subsistence. For example, in Myanmar the PAL of farmers varies from a vigorous activity level (2.51) during the peak season to a light activity level (1.41) post-harvest. Female PALs tend to be more consistent throughout the year, possibly because of their involvement in domestic chores and children care that is constant (Dufour and Piperata, 2008).

There is a large literature on DR associated with farm mechanisation particularly in the context of modernisation of agriculture and adoption of "Green Revolution" technologies in South Asia. The focus of this literature was on demonstrating the efficacy and benefits of mechanisation on the physiology of work - using indicators for effort such as heart rate, energy expenditure, Total Cardiac Cost of Work and Physiological Cost of work, e.g., Nag et al. (1980), Gite and Singh (1997), Nag and Nag (2004), Singh et al. (2007), Mohanty, Behera and Satpathy (2008), Kishtwaria and Rana (2012). These studies regarded DR as a desirable end in itself; they do not typically draw links with potential nutritional impacts.

Gillespie and Kadiyala (2012) found only a limited number of studies that relate employment in agriculture to nutrition and health outcomes. These studies have attempted to classify the energy costs of daily household and agricultural activities, to assess adaptations to seasonality, to assess the impact of activity and food intakes on neo-natal size and to look at differences in thinness according to occupational pattern and gender. Bains, Kaur and Mann (2002) and Rao, Gokhale and Kanade (2007) estimated energy expenditure in rural women using FAO physical activity ratios (PARs). Their key finding was that most tasks undertaken by rural women involved light to moderate levels of activity contrary to the common assumption that their work involves vigorous (heavy) activity levels. Barker et al. (2006) found that women in agricultural families were thinner than women in non-agricultural families and women in agricultural families were 
more likely to be engaged full time in farming activities in addition to carrying the burden of household chores. Durmin, Drummond and Satyanarayana (1990) found that seasonality affects both energy expenditure and food intake with the lean season being associated with lower basal metabolic rate (BMR) and capacity for physical activity. Headey, Chiu and Kadiyala (2011) found that activity characteristics have a significant association with adult BMI. Analysing data from the National Family Health Survey-3 of India, they found that a shift from agriculture to unskilled manual labour was associated with a higher BMI of 0.08 , while a shift to services was associated with a higher BMI of 0.27 and a shift to sale of produce with a higher BMI of 0.29 . The effects of a changing pattern of occupational physical activity were sizable compared to the effects of other factors such as moving up wealth quintiles. Griffith and Bentley (2001) found that women working in agriculture in India were 1.52 times more likely to be underweight than those who are not. Johnston et al. (2018) reviewed the role of time-use as a determinant of nutritional outcomes in rural areas of LMICs. They find that women play a key role in agriculture in terms of time commitments. However, agricultural interventions may not improve nutritional outcomes if they do not take time constraints faced by women into account, as well as the trade-off between productive and reproductive activities and its implications for maternal and child nutrition. While patterns of time-use affect nutritional outcomes, there is no consensus on the nature of impacts because households and household members respond to increased time-burdens and workloads in different ways. To the extent that time-use patterns are likely to be associated with patterns of physical activity, the review also highlights the link between energy expenditure patterns and nutritional outcomes.

A series of systematic reviews have failed to find a clear link between agricultural interventions and nutritional improvements (Webb and Kennedy, 2014). This has been attributed to the lack of sufficient rigorous research and evaluation (Girard et al., 2012; Ruel and Alderman, 2013). They make a case for research to focus on the channels and pathways of impact of agricultural interventions rather than on the size and direction of impacts. More recent research has attempted to delineate and examine the specific pathways of impact from agricultural 
interventions to nutritional improvements, bringing into focus the energy expenditure dimension in understanding agriculture-nutrition linkages. Gillespie and Kadiyala (2012) identify several agricultural nutrition pathways their analysis of agriculture-nutrition disconnect in India. Ruel et al. (2013) summarise these into six key pathways which operate via (1) agriculture as a source of food (2) agriculture as a source of income through wages earned and marketing of produce (3) food prices affecting the incomes of net sellers and the ability of net buyers to ensure household food security (4) women's socio-economic status and their ability to influence household decision making and intra household allocation of food, health and care (5) women's ability to manage care, feeding and health of young children and (6) women's own nutritional status where their work related energy expenditure exceeds their intakes, their dietary diversity is compromised or their agricultural practices are hazardous to their health (and consequently to their nutrition). While the last pathway recognises the role of energy expenditure patterns in determining nutritional outcomes, it has received little attention in the empirical literature. The link between physical activity levels and calorie requirements has been recognised in the literature which examines the low income elasticity of calorie consumption observed in India and other developing countries. Deaton and Dreze (2009) argue that an important explanation of the declining trend in calorie consumption observed in India across the distribution of real per capital expenditure may lie in the declining levels of physical activity in the rural population owing to improved infrastructure and health environment. The energy expenditure profiles of men and women in rural households developed in this paper can be used to incorporate the energy expenditure dimension in understanding agriculture-nutrition linkages.

\section{Data and methods}

\subsection{Data}

Data were collected from predominantly agricultural rural communities in two LMICs - Ghana and India. In Ghana the two selected communities were in the Wa municipality in the Upper West 
region. Situated in Northern Ghana, this is part of the guinea savannah vegetation belt dominated by grassland with scattered drought resistant trees. The area's economy is predominantly agrarian -- $80 \%$ of the population is engaged in agriculture - and the major crops grown in the area are maize, sorghum, millet, groundnut and cowpea. Goat, sheep, pigs and poultry are the main livestock in the area. In India, we selected the households from two villages in Jogulamba Gadwal district in Telangana State, located in the southern Telangana agro-climatic zone which is characterised by red soil track and predominantly rainfall-dependent crop production. The area's economy is agrarian with about $82 \%$ of the population engaged in agriculture. The principal crops grown in the zone include sorghum, cotton, rice, red gram, sesame, maize, castor, safflower and groundnut.

In each country, we selected 10 households involved in rainfed agriculture and 10 households involved in irrigated agriculture. The data collection was spread over the period May 2017 to November 2018 as the cropping season was different in the two countries and for the rainfed and agricultural households. We invited the head of the household and the spouse to participate in the study and provide data on energy expenditure, time-use and food intakes over four nonconsecutive weeks across the agricultural season. To be part of the study, respondents had to be economically active and aged between 16-64 years. The weeks were selected to capture four key phases of the cropping cycle: land preparation, sowing and seeding, land maintenance, and harvest. In each country we therefore collected data from 40 individuals for 27 days each for a total of 1,030 full days.

To collect energy expenditure data, the respondents in the selected households were required to wear an accelerometer for the four weeks in which data was collected. We used the ActiGraph GT3X+ device, a research-grade accelerometer. Participants were instructed to wear the accelerometry devices around the waist while they were awake for seven consecutive days during each agricultural phase ${ }^{1}$. The raw movement data (acceleration along the three axes) downloaded 
from the accelerometers was initially compressed into 3 second epochs and then to one-hour intervals to match the interval for the time use data. The movement data is converted into activity energy expenditure for each hour using the Freedson et al. (1998) algorithm in the Actilife ${ }^{\mathrm{TM}}$ software. The total energy expenditure (TEE) is derived by adding the basal metabolic rate (BMR) for every individual derived by the Harris-Benedict equation (Harris and Benedict, 1918). For activities typical of rural households in the sample, the aggregation of the data into one-hour intervals does not affect the accuracy of the energy expenditure estimates derived (Chen and Basset, 2005). The physical activity in each hour is then split into time spent in light, moderate, vigorous and very vigorous activity using "cut points" or thresholds for classifying the intensity of the activity (based on Sasaki et al., 2011)2 ${ }^{2}$ The reliability and validity of ActiGraph devices have been extensively assessed (Santos-Lozano et al., 2013; Sasaki et al., 2011) and these devices have been used in multiple studies involving free-living humans in various settings (Keino et al., 2014; Pawlowski et al., 2016; Zanello et al., 2017). We restrict our dataset to individual/days that have less than 3 hours of non-compliance (non-wear) time throughout the waking hours. On account of the daily visits of the enumerators, compliance in wearing the accelerometers was remarkably high, 97\% and 93\% in Ghana and India respectively.

Data on energy expenditure were integrated with data on time-use and food intakes collected through a 24-hour recall based questionnaire administered daily to the respondents. The full dataset is publicly available (Zanello et al., 2019). Activities were classified into five macro categories (Domestic, Economic, Personal, Social and Sleeping/Resting) and further into 15 micro-categories. The conversion of food intake to calories was done using food composition tables. For Ghana, we refer to the National Nutrient Database for Standard Reference (USDA, 2017 https://ndb.nal.usda.gov/ndb/) and for India, we refer to Bowen et al. (2011).

\footnotetext{
2 The cut points are based on 'count per minute' (CPM), a measure of the frequency and intensity of the raw acceleration. The categorisation of activities is then defined as follows: light (0 - 2690 CPM), moderate (2691 - 6166 $\mathrm{CPM})$, vigorous (6167 - $9642 \mathrm{CPM}$ ) and very vigorous (> $9643 \mathrm{CPM}$ ). Given the negligible cases of very vigorous activities in our sample $(<1 \%)$, we aggregated this measure within the 'vigorous' activities.
} 


\subsection{Methods}

To relate patterns of physical activity we model the physical activity level (PAL), defined as the ratio of TEE to BMR, as a function of the time spent in light, moderate and vigorous activity along with other household and individual characteristics as explanatory variables. The proportions of time spent in different activity categories constitute "compositional" variables, because the proportions always sum to one, and the increase in the proportion of time spent in one activity category inevitably involves a decrease in the proportion of time spent in other activities.

When compositional variables are present as explanatory variables, the conventional OLS method does not allow for consistent estimation due to multicollinearity and the adding up constraints. The coefficients obtained through an OLS estimation cannot be meaningfully interpreted as the effect of a one-unit change in the explanatory compositional variable holding all the other compositional variables constant. We, therefore, use methods from compositional data analysis (Aitchison, 1982) which are now extensively used in studying the effects of time spent in physical activity or other behaviours (Chastin et al., 2015) - specifically we use compositional regression with the isometric log ratio (ilr) transformation of the compositional explanatory variables. The values of the ilr transformed variables depend on the sequence in which the variables are taken up for transformation. Therefore, this approach requires estimating a series of models in which each proportion (i.e., proportion of time spent in light, moderate or vigorous activity) is treated as the "first" compositional variable by turn.

To assess the impact of a change in the proportion of time spent in light activity on PAL, we ilr transform the compositional variables treating the proportion of time spent on light activity as the first compositional variable. This method allows us to consistently estimate the effect of a change in the proportion of time spent in one activity category with a concurrent change in the proportion of time spent on other activity categories (i.e., while observing the constraint that the proportions add up to one or the number of minutes spent on different categories of activities adds up to 1440 minutes). The multiple linear regression can be written as: 


$$
P A L=\beta_{0}+\beta_{i=1}^{D-1} z_{i}+I N D+H H+C O N T R O L+\varepsilon_{i}
$$

where D is the number of activity categories (in this case 3 - light, moderate, vigorous) and

$$
z_{i}=\sqrt{\frac{D-j}{D-j+1}} \cdot \ln \left(\frac{x_{i}}{\sqrt[D-j]{\Pi_{j=i+1}^{D} x_{j}}}\right)
$$

for $j=1,2, \ldots, D-1$ and $\mathrm{x}_{\mathrm{i}}$ is the number of minutes spent in each activity category during the day and $\sum \mathrm{x}_{\mathrm{i}}=1440$ minutes.

We estimated three sets of regression models - ilr transforming the proportions treating the proportion of time spent on light, moderate and vigorous activity by turn as the first compositional variable. Each model includes a vector (IND) capturing individual characteristics (age, sex, self-reported health status), household characteristics (HH) such as land endowment, agricultural system (rainfed or irrigated), livestock ownership, household composition, wealth, and controls (CONTROL) for the sequential day of wearing the accelerometer, agricultural season (land preparation, sowing/seeding, land maintenance, harvest) day of the week, and the hours of non-wear time in a day. In compositional regressions, the main coefficient of interest is the coefficient of the first ilr transformed variable $(z 1)$ which shows the effect of a change in the proportion of the first compositional variable with a corresponding change in the proportion of the remaining compositional variables (e.g., the effect of an increase in the proportion of time spent in light activity with a corresponding decrease in the proportion of time spent in moderate and vigorous activity). We estimate and report both a linear regression and fixed effect regression (including only the CONTROL) to exploit the panel nature of our data.

In our estimations we assume that an increase in the proportion of time spent in one activity is accompanied by an equi-proportional reduction in the proportion of time spent on other activities (Dumuid et al., 2019). Using our regression results we compute the elasticities of PAL with respect to DR - which we define as substitution of light activity for moderate or vigorous activity. 
To present the implications of our estimates in a more intuitive way, we use our base model to predict the effect of increasing 60 mins of light activity in a day with an equi-proportional reduction of moderate and vigorous activities on PAL. This could be done increasing the time spent in light activity by 60 mins and reducing proportionally the time spent in other activities by $1-s$

$$
\Delta \hat{y}=\widehat{\beta_{1}} \cdot \sqrt{\frac{D-1}{D}} \cdot \ln \left(\frac{60}{1-s}\right)
$$

where $s=60 \cdot \frac{x_{1}}{1-x_{1}}$ with $\mathrm{x}_{1}$ being the number of minutes spent initially in light activities.

We compare the effects of DR -increasing light activity by 60 minutes replacing moderate and vigorous activity - by key household characteristics (wealth, landholding size, agricultural system (irrigated or rainfed) and gender) and test whether the differences in the effects on PAL are significant.

The relative energy intensities of moderate/ vigorous (drudgery causing) and light activities for men and women in different household categories are important parameters that determine the potential for DR. The data derived from accelerometers provides us the number of minutes in each hour which is spent light, moderate, vigorous activity. However, the energy intensity of light/moderate/vigorous activities is not directly available from the accelerometer data. We estimate the relative energy intensities of these activities for men and women in each household category through compositional regressions with AEE as the dependent variable and the ilrtransformed minutes in each hour (summing to 60 minutes) spent in each category of activity as the explanatory variables, with light, moderate, vigorous activities being treated as the first compositional variable by turn. The coefficients of these compositional regressions provide an index of the relative energy intensity of light, moderate and vigorous activities for men and women in different household categories. 


\subsection{Limitations}

We believe that the energy expenditure data generated in this study through the use of waistworn accelerometers is robust, given that respondents' compliance in wearing the accelerometers was fairly high.

Our small sample size of 20 households in each country is not representative of the rural population in these countries. The distinction that we make between large landholding households versus small land holding households, richer versus poorer households are all distinctions made within the group of small farmers that we have included in the study. Given the small number of households sampled in each country, the comparisons between different categories of households may not be robust. However, it should be noted that we work with day level data and we have a 1030 day-level observations for individuals (men and women) in each country with 27 days level observations for each individual. Comparisons between different categories of households are based on day level observations.

While we collected data on energy expenditure and time-use in different phases of the agricultural season, we have not analysed the seasonal differences in PAL for the sample. There may be important seasonality effects which are not captured in our aggregate results. We have also not considered the activity categories (productive, reproductive or leisure/rest) within or across which substitutions are made to achieve DR. We are aware that just as DR can impact nutritional status (calorie adequacy) by reducing energy requirements, improved nutritional status can also influence physical activity. However, these effects are likely to be observed consequent to nutritional improvements. Given our focus on the immediate reductions in energy requirements associated with DR facilitated by interventions such as mechanisation, we have not examined the impacts of nutritional status on physical activity levels.

The biases in self-reported recall-based data on food intakes are well recognised in the literature. Food intake data is recognised to be subject to a significant under-reporting bias which may vary by gender and by anthropometric characteristics. In our study it is possible that the under- 
reporting of food intakes may have been larger for men than for women - particularly in relation to food eaten outside the home and calories derived from alcohol consumption. For women, especially in deprived households, there could be a tendency to overstate food consumption or a reluctance to acknowledge lower food intakes. In the analysis in this paper we use the food intake data only to assess the average calorie deficits for men and women in the two countries.

\section{Results}

\subsection{Descriptive Statistics}

Table-1 presents the descriptive statistics of rural households sampled in Ghana and India for the study.

Table-1: Descriptive Statistics of Rural Households in Ghana and India

\begin{tabular}{lllll} 
& Ghana & \multicolumn{3}{l}{ India } \\
\cline { 2 - 5 } & Mean & SD & Mean & SD \\
\hline Age of the head of the household (years) & 39.09 & $(9.56)$ & 39.60 & $(10.38)$ \\
Literacy of the head (whether literate) & 0.18 & $(0.39)$ & 0.30 & $(0.47)$ \\
Household size & 7.59 & $(3.69)$ & 4.30 & $(1.59)$ \\
Asset index & 0.00 & $(1.87)$ & 0.00 & $(1.73)$ \\
Tropical Livestock Units & 3.58 & $(5.92)$ & 1.95 & $(2.48)$ \\
Irrigation & 1.45 & $(0.51)$ & 1.50 & $(0.51)$ \\
Number of elderly & 0.23 & $(0.61)$ & 0.10 & $(0.31)$ \\
Number of adults & 3.05 & $(1.36)$ & 2.70 & $(1.08)$ \\
Number of adolescents & 1.18 & $(1.18)$ & 0.35 & $(0.75)$ \\
Number of children & 2.73 & $(1.58)$ & 1.10 & $(1.02)$ \\
Number of infants & 0.41 & $(0.50)$ & 0.05 & $(0.22)$ \\
Total land holding (Acres) & 4.52 & $(3.85)$ & 4.05 & $(3.16)$ \\
Distance from the nearest all weather/tarmac road (Km) & 2.50 & $(2.25)$ & 0.77 & $(2.24)$ \\
Distance from the nearest local trading centre (Km) & 5.93 & $(2.40)$ & 8.10 & $(4.01)$ \\
Km from the nearest major products market (Km) & 3.68 & $(2.79)$ & 7.90 & $(4.31)$ \\
Number of households & 22 & & 20 & \\
\hline
\end{tabular}

The households sampled in both countries were small farmer agricultural households. The average age of the household head was 39 years. The literacy of household heads was very low in Ghana (18\%) but somewhat higher in India (30\%). The household size and the number of children per household was larger in Ghana than in India. This was possibly owing to extended family units all residing within the same household compound in Ghana. The average landholding ranged from 4-4.5 acres in Ghana and India. Households in both countries were located more than 
$3 \mathrm{kms}$ away from the nearest product markets and trading centres. These distances were the largest in India.

The descriptive statistics of physical activity, energy expenditure and calorie intake for the pooled sample of men and women in the two countries is presented in Table-2.

Table-2: Physical Activity and Energy Expenditure in Ghana and India

\begin{tabular}{lllll} 
& \multicolumn{3}{c}{ Ghana } & \multicolumn{3}{l}{ India } \\
\cline { 2 - 5 } & Mean & SD & Mean & SD \\
\hline Age (years) & 36.46 & $(9.09)$ & 37.41 & $(12.96)$ \\
Height (in cm) & 167.79 & $(8.36)$ & 156.54 & $(8.68)$ \\
Weight (in kg) & 59.40 & $(5.52)$ & 52.43 & $(9.63)$ \\
Food intakes (kcals/day) & $2,025.54$ & $(769.68)$ & $1,692.24$ & $(553.24)$ \\
BMI (Kg/m ${ }^{2}$ ) & 21.13 & $(1.77)$ & 21.30 & $(2.96)$ \\
Proportion of undernourished & $2.5 \%$ & & $22.5 \%$ & \\
(BMI< 18.5) & $1,136.73$ & $(412.64)$ & 703.58 & $(383.90)$ \\
AEE (kcal/d) & $2,521.06$ & $(468.47)$ & $1,940.93$ & $(486.67)$ \\
TEE (kcal/d) & $1,384.34$ & $(156.29)$ & $1,237.35$ & $(196.01)$ \\
BMR & 1.83 & $(0.29)$ & 1.57 & $(0.28)$ \\
PAL & 0.85 & $(0.05)$ & 0.89 & $(0.06)$ \\
Light activity (\%) & 0.13 & $(0.05)$ & 0.10 & $(0.05)$ \\
Moderate activity (\%) & 0.02 & $(0.02)$ & 0.01 & $(0.01)$ \\
Vigorous activity (\%) & $15,737.65$ & $(5557.28)$ & $11,033.72$ & $(5331.35)$ \\
Steps / day & 26.06 & $(3.99)$ & 26.46 & $(1.91)$ \\
Number of days (out of 28) & 23.92 & $(0.33)$ & 23.83 & $(0.48)$ \\
Wear compliance (over 24 hrs) & 23.96 & \\
\hline
\end{tabular}

1. Note: Statistics based on valid days (less than 3 hours of non-wear time).

The mean BMI for the pooled sample of men and women was above 21 in both countries which is well above the WHO underweight/undernutrition threshold of 18.5 (WHO, 1995). Patterns of physical activity were similar in both countries with $85-89 \%$ of time spent in light physical activity, $10-13 \%$ in moderately intensive activity and 1-2\% in vigorous physical activity.

Comparisons of physical activity, energy expenditure and calorie intakes between men and women are shown in Table-3. 
Table-3: Differences by Gender in Physical Activity and Energy Expenditure in Ghana and India

\begin{tabular}{|c|c|c|c|c|c|c|}
\hline & \multicolumn{3}{|l|}{ Ghana } & \multicolumn{3}{|l|}{ India } \\
\hline & Males & Females & & Males & Females & \\
\hline & $\operatorname{Mean}(\mathrm{SD})$ & Mean (SD) & Diff. & Mean (SD) & Mean (SD) & Diff. \\
\hline Age & $\begin{array}{l}39.66 \\
(9.12)\end{array}$ & $\begin{array}{l}33.10 \\
(7.76)\end{array}$ & $6.56^{* * *}$ & $\begin{array}{l}40.59 \\
(15.06)\end{array}$ & $\begin{array}{l}34.00 \\
(9.49)\end{array}$ & $6.59 * * *$ \\
\hline Height (in $\mathrm{cm}$ ) & $\begin{array}{l}172.60 \\
(5.89)\end{array}$ & $\begin{array}{l}162.73 \\
(7.54)\end{array}$ & $9.87^{* * *}$ & $\begin{array}{l}162.75 \\
(7.18)\end{array}$ & $\begin{array}{l}150.32 \\
(4.59)\end{array}$ & $12.43^{* * *}$ \\
\hline Weight (in kg) & $\begin{array}{l}61.84 \\
(5.04)\end{array}$ & $\begin{array}{l}56.83 \\
(4.78)\end{array}$ & $5.01^{* * *}$ & $\begin{array}{l}58.41 \\
(8.83)\end{array}$ & $\begin{array}{l}46.47 \\
(5.95)\end{array}$ & $11.94 * * *$ \\
\hline Food intakes (kcals/day) & $\begin{array}{l}2,118.43 \\
(770.31)\end{array}$ & $\begin{array}{l}1,928.02 \\
(757.59)\end{array}$ & $190.41^{* * *}$ & $\begin{array}{l}1,780.82 \\
(567.28)\end{array}$ & $\begin{array}{l}1,604.34 \\
(524.89)\end{array}$ & $176.48^{* * *}$ \\
\hline $\mathrm{BMI}\left(\mathrm{Kg} / \mathrm{m}^{2}\right)$ & $\begin{array}{l}20.76 \\
(1.30)\end{array}$ & $\begin{array}{l}21.52 \\
(2.08)\end{array}$ & $-0.76^{* * *}$ & $\begin{array}{l}22.05 \\
(3.20)\end{array}$ & $\begin{array}{l}20.57 \\
(2.49)\end{array}$ & $1.48^{* * *}$ \\
\hline AEE (kcal/d) & $\begin{array}{l}1,167.89 \\
(475.54)\end{array}$ & $\begin{array}{l}1,104.01 \\
(331.44)\end{array}$ & $63.88^{*}$ & $\begin{array}{l}786.07 \\
(447.67)\end{array}$ & $\begin{array}{l}625.35 \\
(291.35)\end{array}$ & $160.72^{* * *}$ \\
\hline TEE (kcal/d) & $\begin{array}{l}2,671.75 \\
(510.96)\end{array}$ & $\begin{array}{l}2,362.87 \\
(356.72)\end{array}$ & $308.88^{* * *}$ & $\begin{array}{l}2,189.34 \\
(496.84)\end{array}$ & $\begin{array}{l}1,698.59 \\
(331.90)\end{array}$ & $490.75^{* * *}$ \\
\hline BMR & $\begin{array}{l}1,503.86 \\
(100.67)\end{array}$ & $\begin{array}{l}1,258.86 \\
(93.14)\end{array}$ & $245.00^{* * *}$ & $\begin{array}{l}1,403.28 \\
(120.79) \\
\end{array}$ & $\begin{array}{l}1,073.24 \\
(86.52)\end{array}$ & $330.04^{* * *}$ \\
\hline .PAL & $\begin{array}{l}1.77 \\
(0.30)\end{array}$ & $\begin{array}{l}1.88 \\
(0.27)\end{array}$ & $-0.11^{*}$ & $\begin{array}{l}1.56 \\
(0.31)\end{array}$ & $\begin{array}{l}1.58 \\
(0.25)\end{array}$ & -0.02 \\
\hline Light activity (\%) & $\begin{array}{l}0.85 \\
(0.06)\end{array}$ & $\begin{array}{l}0.84 \\
(0.05)\end{array}$ & $0.01^{* * *}$ & $\begin{array}{l}0.90 \\
(0.06)\end{array}$ & $\begin{array}{l}0.89 \\
(0.05)\end{array}$ & 0.01 \\
\hline Moderate activity (\%) & $\begin{array}{l}0.13 \\
(0.05)\end{array}$ & $\begin{array}{l}0.14 \\
(0.04)\end{array}$ & $-0.01 * * *$ & $\begin{array}{l}0.09 \\
(0.05)\end{array}$ & $\begin{array}{l}0.10 \\
(0.04)\end{array}$ & -0.01 \\
\hline Vigorous activity (\%) & $\begin{array}{l}0.02 \\
(0.02)\end{array}$ & $\begin{array}{l}0.02 \\
(0.01)\end{array}$ & $0.005^{* *}$ & $\begin{array}{l}0.01 \\
(0.01)\end{array}$ & $\begin{array}{l}0.01 \\
(0.01)\end{array}$ & 0.001 \\
\hline Steps / day & $\begin{array}{l}14,684.20 \\
(5,257.62)\end{array}$ & $\begin{array}{l}16,843.58 \\
(5,652.65)\end{array}$ & $2159.38 * * *$ & $\begin{array}{l}12,367.11 \\
(6,156.59)\end{array}$ & $\begin{array}{l}9,782.41 \\
(4,025.08)\end{array}$ & $2584.7^{* * *}$ \\
\hline Number of days (out of 28) & $\begin{array}{l}26.57 \\
(3.51)\end{array}$ & $\begin{array}{l}25.52 \\
(4.37)\end{array}$ & $1.05^{* * *}$ & $\begin{array}{l}26.36 \\
(1.87)\end{array}$ & $\begin{array}{l}26.57 \\
(1.92)\end{array}$ & -0.21 \\
\hline Wear compliance (over 24 hrs) & $\begin{array}{l}23.91 \\
(0.35)\end{array}$ & $\begin{array}{l}23.93 \\
(0.31)\end{array}$ & -0.02 & $\begin{array}{l}23.84 \\
(0.45)\end{array}$ & $\begin{array}{l}23.81 \\
(0.52)\end{array}$ & 0.03 \\
\hline
\end{tabular}

2. Statistics based on valid days (less than 3 hours of non-wear time). Asterisks show level of significance $* * *=$ significant at $0.1 \%$ level, ${ }^{* *}=$ significant at $1 \%$ level and ${ }^{*}=$ significant at $5 \%$ level. Standard deviations in parenthesis.

Women have a significantly higher mean BMI than men in Ghana; conversely, in India it is men

who have the higher BMI. Expectedly, AEE and TEE for men are significantly higher than for women in both countries. However, Physical Activity Level (PAL) is significantly higher for women than for men in both countries, which suggests that rural livelihoods call for greater physical effort from women (FAO, 2011). Food intakes (calories per capita per day) are significantly higher for men than for women in the two countries. While calorie intake data from recall based surveys may be subject to under/over reporting biases, a comparison of TEE with kcal intake suggests the prevalence of calorie deficits for both men and women in the two countries. The average calorie deficit is in the range of $20 \%$ for both men and women in Ghana, while it is $20 \%$ for men and $5 \%$ women in India. The proportions of time spent in light, moderate and vigorous activity by men and women are similar in both countries, although some differences 
in the proportion of time spent in different activity categories are statistically significant. Women and men spend more than $85 \%$ of their time in light activities, $9-13 \%$ in moderate activities and only 1-2\% in vigorous activities. The proportion of time spent in moderate and vigorous activities is lower in India.

Table-4 shows the patterns of energy expenditure and time use for men and women in the five different activity categories for our sample households in Ghana and India.

Table-4: Proportion of energy expenditure and time use patterns by activity in Ghana and India

\begin{tabular}{lllllllll} 
& \multicolumn{1}{l}{ Ghana } & \multicolumn{7}{l}{ India } \\
\cline { 2 - 10 } & Men & \multicolumn{3}{l}{ Women } & Men & & Women \\
\cline { 2 - 10 } & AEE & Time & AEE & Time & AEE & Time & AEE & Time \\
\cline { 2 - 10 } Domestic activities & $\mathbf{0 . 0 3}$ & $\mathbf{0 . 0 2}$ & $\mathbf{0 . 2 9}$ & $\mathbf{0 . 2 6}$ & $\mathbf{0 . 0 2}$ & $\mathbf{0 . 0 3}$ & $\mathbf{0 . 2 0}$ & $\mathbf{0 . 2 0}$ \\
Child / adult care & 0.00 & 0.00 & 0.02 & 0.02 & 0.00 & 0.00 & 0.02 & 0.02 \\
Getting services & 0.00 & 0.00 & 0.00 & 0.00 & 0.00 & 0.00 & 0.00 & 0.00 \\
Household chores & 0.03 & 0.02 & 0.26 & 0.24 & 0.02 & 0.02 & 0.18 & 0.18 \\
Travelling & 0.00 & 0.00 & 0.00 & 0.00 & 0.00 & 0.00 & 0.00 & 0.00 \\
Economic activities & $\mathbf{0 . 6 6}$ & $\mathbf{0 . 5 2}$ & $\mathbf{0 . 4 5}$ & $\mathbf{0 . 3 6}$ & $\mathbf{0 . 6 3}$ & $\mathbf{0 . 5 1}$ & $\mathbf{0 . 5 2}$ & $\mathbf{0 . 4 1}$ \\
Crop production & 0.40 & 0.28 & 0.22 & 0.18 & 0.38 & 0.30 & 0.33 & 0.26 \\
Livestock & 0.01 & 0.01 & 0.00 & 0.00 & 0.07 & 0.06 & 0.02 & 0.01 \\
Marketing & 0.03 & 0.03 & 0.03 & 0.02 & 0.00 & 0.00 & 0.00 & 0.00 \\
Off-farm & 0.03 & 0.02 & 0.01 & 0.01 & 0.03 & 0.02 & 0.03 & 0.02 \\
Processing & 0.04 & 0.04 & 0.07 & 0.06 & 0.06 & 0.05 & 0.09 & 0.07 \\
Travelling & 0.14 & 0.13 & 0.13 & 0.10 & 0.08 & 0.07 & 0.06 & 0.05 \\
Individual activities & $\mathbf{0 . 0 7}$ & $\mathbf{0 . 0 8}$ & $\mathbf{0 . 1 0}$ & $\mathbf{0 . 1 0}$ & $\mathbf{0 . 1 7}$ & $\mathbf{0 . 1 8}$ & $\mathbf{0 . 1 6}$ & $\mathbf{0 . 1 6}$ \\
Eating & 0.03 & 0.03 & 0.03 & 0.03 & 0.11 & 0.11 & 0.12 & 0.11 \\
Leisure & 0.01 & 0.01 & 0.01 & 0.01 & 0.03 & 0.04 & 0.02 & 0.03 \\
Medical care & 0.00 & 0.00 & 0.00 & 0.00 & 0.00 & 0.00 & 0.00 & 0.00 \\
Personal care & 0.04 & 0.04 & 0.06 & 0.06 & 0.02 & 0.03 & 0.02 & 0.02 \\
Travelling & 0.00 & 0.00 & 0.00 & 0.00 & 0.00 & 0.00 & 0.00 & 0.00 \\
Sleeping and resting & $\mathbf{0 . 1 1}$ & $\mathbf{0 . 2 1}$ & $\mathbf{0 . 0 8}$ & $\mathbf{0 . 1 7}$ & $\mathbf{0 . 0 7}$ & $\mathbf{0 . 1 5}$ & $\mathbf{0 . 0 6}$ & $\mathbf{0 . 1 4}$ \\
Resting & 0.10 & 0.19 & 0.07 & 0.17 & 0.06 & 0.14 & 0.06 & 0.14 \\
Sleeping & 0.01 & 0.01 & 0.00 & 0.01 & 0.00 & 0.00 & 0.00 & 0.00 \\
Social activities & $\mathbf{0 . 1 4}$ & $\mathbf{0 . 1 7}$ & $\mathbf{0 . 0 9}$ & $\mathbf{0 . 1 0}$ & $\mathbf{0 . 1 1}$ & $\mathbf{0 . 1 3}$ & $\mathbf{0 . 0 6}$ & $\mathbf{0 . 0 8}$ \\
Eating & 0.01 & 0.03 & 0.02 & 0.03 & 0.04 & 0.06 & 0.04 & 0.06 \\
Religious activities & 0.03 & 0.03 & 0.02 & 0.02 & 0.01 & 0.01 & 0.00 & 0.00 \\
Social-Community & 0.06 & 0.09 & 0.04 & 0.04 & 0.05 & 0.05 & 0.01 & 0.01 \\
Travelling & 0.03 & 0.02 & 0.02 & 0.01 & 0.01 & 0.01 & 0.00 & 0.00 \\
\hline
\end{tabular}

Notes: AEE = Activity Energy Expenditure. Data on energy expenditure and time use refer to daytime activities (4 am to 10 pm in Ghana and 5 am to $10 \mathrm{pm}$ in India) and include both weekdays and weekends.

Table- 4 shows large differences between men and women in the proportion of time and energy they spend on domestic work. Women spend a fifth to a quarter of their time and energy on domestic activities, while men spend just $2-3 \%$ of their time and energy on these activities. For women the dominant element of domestic activities is constituted by household chores. Childcare appears to take up only $2 \%$ of energy and time, but that probably reflects the fact that childcare is often performed in parallel with household chores and may not always get captured as a 
separate activity in the data. The limited involvement of men in domestic work is striking in both Ghana and India. The proportions of time and energy spent on reproductive work are similar suggesting that domestic activities are not relatively energy intensive.

Men in Ghana and India spend half of their time on economic activities which accounts for nearly two-thirds of their energy expenditure. However, in both countries, women's participation in economic activities is also substantial - with $40 \%$ of their time and nearly $50 \%$ of their energy accounted for by economic activities. Crop production and travel related to economic activities are the dominant components of productive work for both men and women. Processing is one activity where women devote a larger share of time and energy than men. Somewhat surprisingly, livestock is not a major contributor to time and energy use in these agricultural households in both Ghana and India. This may be on account of livestock activities getting subsumed under household chores for women. The larger proportion of energy in relation to time for economic activities shows that these activities tend to be relatively more energy intensive.

Taken together, domestic and economic activities (activities which contribute to household reproduction) account for $54 \%$ of time use and $65-69 \%$ of energy expenditure for men in the two countries. For women these activities account for for more than $60 \%$ of time and $72-74 \%$ of energy expenditure. This suggests that women carry a larger share of the work burden in rural households in both countries. Men devote nearly $27 \%-38 \%$ of their time to social activities and resting while women have a substantially less time $(22 \%-28 \%)$ for these activities. The larger involvement of women in domestic activities comes mainly at the expense of social activities and resting and not at the expense of participation in economic activities. 
Table-5: Contribution of activities to drudgery in rural households in Ghana and India proportion of time spent in moderate/vigorous activity

\begin{tabular}{lllll} 
& & \multicolumn{2}{l}{ India } & \\
\cline { 2 - 5 } & Men & Women & Men & Women \\
\hline Domestic activity & $\mathbf{0 . 0 3}$ & $\mathbf{0 . 2 8}$ & $\mathbf{0 . 0 2}$ & $\mathbf{0 . 1 9}$ \\
Child / adult care & 0.00 & 0.02 & 0.00 & 0.02 \\
Getting services & 0.00 & 0.00 & 0.00 & 0.00 \\
Household chores & 0.03 & 0.26 & 0.02 & 0.17 \\
Travelling & 0.00 & 0.00 & 0.00 & 0.00 \\
Economic activities & $\mathbf{0 . 6 9}$ & $\mathbf{0 . 4 7}$ & $\mathbf{0 . 6 5}$ & $\mathbf{0 . 5 5}$ \\
Crop production & 0.45 & 0.22 & 0.40 & 0.34 \\
Livestock & 0.02 & 0.00 & 0.07 & 0.02 \\
Marketing & 0.02 & 0.03 & 0.00 & 0.00 \\
Off-farm & 0.03 & 0.01 & 0.03 & 0.03 \\
Processing & 0.04 & 0.08 & 0.07 & 0.10 \\
Travelling & 0.13 & 0.13 & 0.08 & 0.06 \\
Individual activities & $\mathbf{0 . 0 6}$ & $\mathbf{0 . 0 9}$ & $\mathbf{0 . 1 6}$ & $\mathbf{0 . 1 4}$ \\
Eating related & 0.03 & 0.02 & 0.11 & 0.12 \\
Leisure & 0.00 & 0.01 & 0.03 & 0.01 \\
Medical care & 0.00 & 0.00 & 0.00 & 0.00 \\
Personal care & 0.03 & 0.06 & 0.02 & 0.01 \\
Travelling & 0.00 & 0.00 & 0.00 & 0.00 \\
Social activities & $\boldsymbol{0 . 2 1}$ & $\boldsymbol{0 . 1 5}$ & $\mathbf{0 . 1 6}$ & $\mathbf{0 . 0 9}$ \\
Eating & 0.01 & 0.02 & 0.04 & 0.03 \\
Religious activities & 0.03 & 0.02 & 0.01 & 0.00 \\
Social-Community & 0.04 & 0.02 & 0.04 & 0.01 \\
Official (survey) & 0.01 & 0.01 & 0.00 & 0.00 \\
Travelling & 0.02 & 0.02 & 0.01 & 0.00 \\
Others & 0.10 & 0.06 & 0.06 & 0.05 \\
\hline
\end{tabular}

Table- 5 shows the contribution that different activities make to drudgery in Ghana and India. This is derived from the contribution that different activities make to the total time spent in moderate/vigorous/very vigorous activity. Economic activities are the major source of drudgery for both men and women, but somewhat less for women. Crop production is the major source of drudgery in economic activities for both men and women. Processing and travelling are the important sources of drudgery in economic activities for both men and women, with processing being a larger source of drudgery for women than for men. Domestic activity is a major source of drudgery for women but not for men. Household chores are the dominant source of drudgery for women in domestic activities. Individual care activities are a greater source of drudgery in India than in Ghana. Social activities (which includes community and religious activities) also make a large contribution to drudgery in Ghana and India, but more so for men. The differences in the source of drudgery suggests that different avenues for drudgery reduction may have to be sought for men and women. 


\subsection{Compositional Regression Results}

The full results of the compositional regression with PAL as the dependent variable, and the Ilrtransformed time use proportion variables along with other covariates, are presented in Tables A and B in the Appendix. As explained in the methods section, we run three separate regressions taking the proportion of time spent in light, moderate and vigorous activity, by turn, as the first part of the composition. The co-efficient of interest in the compositional regressions is the coefficient of the $z_{1}$ variable which shows the effect of variation in proportion of time spent in light activity relative to the remaining components (i.e., proportion of time spent in moderate and vigorous activity). These coefficients are shown in Table- 6 for each of the regressions for the fixed effect panel model (linear regression model result are reported in Appendix).

Table- 6 shows that an increase in the proportion of time spent in light activity with a proportional reduction in time spent in moderate and vigorous activity will lead to a decline in PAL. This effect is larger for Ghana than for India. Similarly, an increase in the proportion of time spent in moderate activity with a proportionate reduction in time spent in vigorous and light activity will lead to an increase in PAL. This effect is smaller for Ghana than for India.

Table-6: Compositional Fixed effects Regression Results - Coefficients of first component time use proportion variables

\begin{tabular}{llc} 
& & \\
\cline { 2 - 3 } & PAL & \\
\cline { 2 - 3 } z1 (Proportion of time spent in light activity as first component) & India \\
& $-0.686^{* * *}$ & $-0.447^{* * *}$ \\
z1 (Proportion of time spent in moderate activity as first component) & $0.433^{* * *}$ & $0.366^{* * *}$ \\
& $(0.046)$ & $(0.033)$ \\
z1 (Proportion of time spent in vigorous activity as first component) & $0.253^{* * *}$ & $0.111^{* * *}$ \\
& $0.033)$ & $(0.017)$ \\
\hline F-test & $77.19^{* * *}$ & $36.62^{* * *}$ \\
R-squared (overall) & 0.85 & 0.76 \\
R-squared (within) & 0.87 & 0.76 \\
R-squared (between) & 0.77 & 0.78 \\
\hline Observations & 1079 & 1051
\end{tabular}

3. Standard errors in parenthesis. Asterisks show level of significance ${ }^{* * *}=$ significant at $1 \%$ level, ${ }^{* *}=$ significant at $5 \%$ level and ${ }^{*}=$ significant at $10 \%$ level. Regressions control for the sequential day of wearing the accelerometer, agricultural season (land preparation, sowing/seeding, land maintenance, harvest) day of the week, and the hours of non-wear time in a day. Robust standard errors. Full specification and OLS model in Appendix. 
These $\mathrm{z}_{1}$ coefficients, however, cannot be interpreted as the effect of a unit change in (e.g., in minutes) in the time spent in the first component activity. However, we can compute the elasticities of PAL with respect to a change in proportion of time spent in light activity by applying the inverse ilr transformation to the coefficients. The elasticities of PAL with respect to changes in the proportion of time spent in light activity for different categories of households and men and women within each category for Ghana and India are presented in Table-7.

Table-7: The DR elasticities of PAL in Ghana and India

\begin{tabular}{|c|c|c|c|c|}
\hline & Ghana & & India & 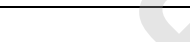 \\
\hline \multirow{3}{*}{ Non-irrigated households } & Men & Women & Men & Women \\
\hline & -3.72 & -2.96 & -5.56 & -3.52 \\
\hline & {$\left[\begin{array}{ll}-4.12 & -3.32\end{array}\right]$} & {$\left[\begin{array}{ll}-3.24 & -2.69\end{array}\right]$} & {$\left[\begin{array}{ll}-6.28 & -4.84]\end{array}\right.$} & {$\left[\begin{array}{ll}-3.91 & -3.13\end{array}\right]$} \\
\hline \multirow[t]{2}{*}{ Irrigated households } & -2.63 & -3.24 & -4.14 & -3.30 \\
\hline & {$\left[\begin{array}{ll}-2.90 & -2.36\end{array}\right]$} & {$\left[\begin{array}{ll}-3.66 & -2.82\end{array}\right]$} & {$\left[\begin{array}{ll}-4.72 & -3.56\end{array}\right]$} & {$\left[\begin{array}{ll}-3.64 & -2.95\end{array}\right]$} \\
\hline \multirow[t]{2}{*}{ Bottom half wealth } & -3.40 & -2.94 & -4.56 & -3.25 \\
\hline & {$\left[\begin{array}{ll}-3.79 & -3.02\end{array}\right]$} & {$\left[\begin{array}{ll}-3.30 & -2.58\end{array}\right]$} & {$\left[\begin{array}{ll}-5.28 & -3.84\end{array}\right]$} & {$\left[\begin{array}{ll}-3.52 & -2.99\end{array}\right]$} \\
\hline \multirow[t]{2}{*}{ Top half wealth } & -2.91 & -3.27 & -5.60 & -3.64 \\
\hline & {$\left[\begin{array}{ll}-3.18 & -2.63\end{array}\right]$} & {$\left[\begin{array}{ll}-3.61 & -2.92\end{array}\right]$} & {$\left[\begin{array}{ll}-6.35 & -4.86\end{array}\right]$} & {$\left[\begin{array}{ll}-4.14 & -3.13\end{array}\right]$} \\
\hline \multirow[t]{2}{*}{ Small landowners } & -2.92 & -2.88 & -5.07 & -3.40 \\
\hline & {$\left[\begin{array}{ll}-3.21 & -2.64\end{array}\right]$} & {$\left[\begin{array}{ll}-3.12 & -2.65\end{array}\right]$} & {$\left[\begin{array}{ll}-5.81 & -4.34\end{array}\right]$} & {$\left[\begin{array}{ll}-3.78 & -3.03\end{array}\right]$} \\
\hline \multirow[t]{2}{*}{ Large landowners } & -3.50 & -3.34 & -4.71 & -3.90 \\
\hline & {$\left[\begin{array}{ll}-3.92 & -3.08\end{array}\right]$} & {$\left[\begin{array}{ll}-3.82 & -2.86\end{array}\right]$} & {$\left[\begin{array}{ll}-5.33 & -4.10\end{array}\right]$} & {$\left[\begin{array}{ll}-4.34 & -3.46\end{array}\right]$} \\
\hline \multirow[t]{2}{*}{ Small dependency ratio } & -3.02 & -3.18 & -5.18 & -3.50 \\
\hline & {$\left[\begin{array}{ll}-3.35 & -2.69\end{array}\right]$} & {$\left[\begin{array}{ll}-3.53 & -2.84\end{array}\right]$} & {$\left[\begin{array}{ll}-5.87 & -4.49\end{array}\right]$} & {$\left[\begin{array}{ll}-3.92 & -3.08\end{array}\right]$} \\
\hline \multirow[t]{2}{*}{ Large dependency ratio } & -3.70 & -3.00 & -5.02 & -3.58 \\
\hline & {$\left[\begin{array}{ll}-4.05 & -3.34\end{array}\right]$} & {$\left[\begin{array}{ll}-3.33 & -2.66\end{array}\right]$} & {$\left[\begin{array}{ll}-5.85 & -4.18\end{array}\right]$} & {$\left[\begin{array}{ll}-3.93 & -3.24\end{array}\right]$} \\
\hline
\end{tabular}

4. Note: $95 \%$ confidence interval in brackets.

The elasticity of PAL (\% change in PAL/\% change in proportion of time spent in light activity) shows the responsiveness of PAL to DR, i.e., change in PAL for a one percent increase in the time spent in light activity substituting for moderate/vigorous activity. As energy requirement (TEE) = PAL x BMR (assumed constant for each respondent) the elasticity of PAL also shows how energy requirement changes with DR. The negative sign indicates the direction of change - DR leads to a decrease in PAL and energy requirement. The elasticity of PAL reflects the difference between the energy intensity of the incremental light activity and the energy intensity of the moderate/vigorous activity that it substitutes. The PAL elasticity, therefore, reflects the DR substitution choices that men and women face in different categories of households.

Table-7 shows that in all categories of households, PAL for men is more responsive to DR than it is for women. This may reflect the differences in the options for DR faced by men and women. 
PAL elasticity also varies across different categories of households. In Ghana, for men PAL is most responsive to DR in non-irrigated households, small landholding households and less wealthy households. However, for women, PAL is most responsive to DR in large landholding households, irrigated households and wealthier households. In India, the PAL elasticity for both men and women are higher than they are in Ghana. For men and women, PAL is most responsive to DR in non-irrigated households, small landholding households and small dependency ratio households.

Figure-1: Predicted change in energy requirement for change in light, moderate and vigorous activity for Ghana (A) and India (B)

A-Ghana

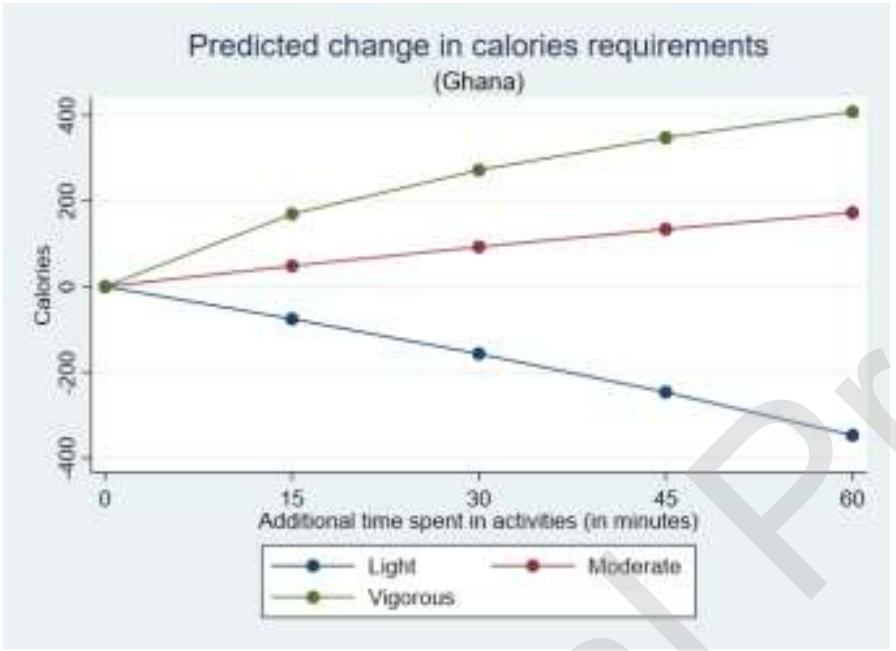

B-India

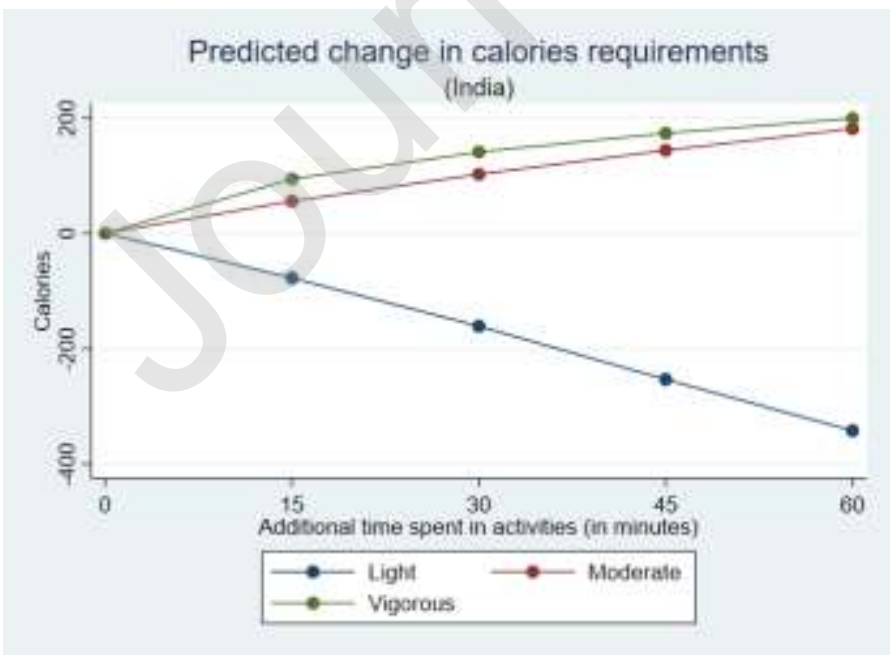


Figure-2: Predicted change in energy requirement for change in light activity by gender for Ghana (A) and India (B)

A -Ghana

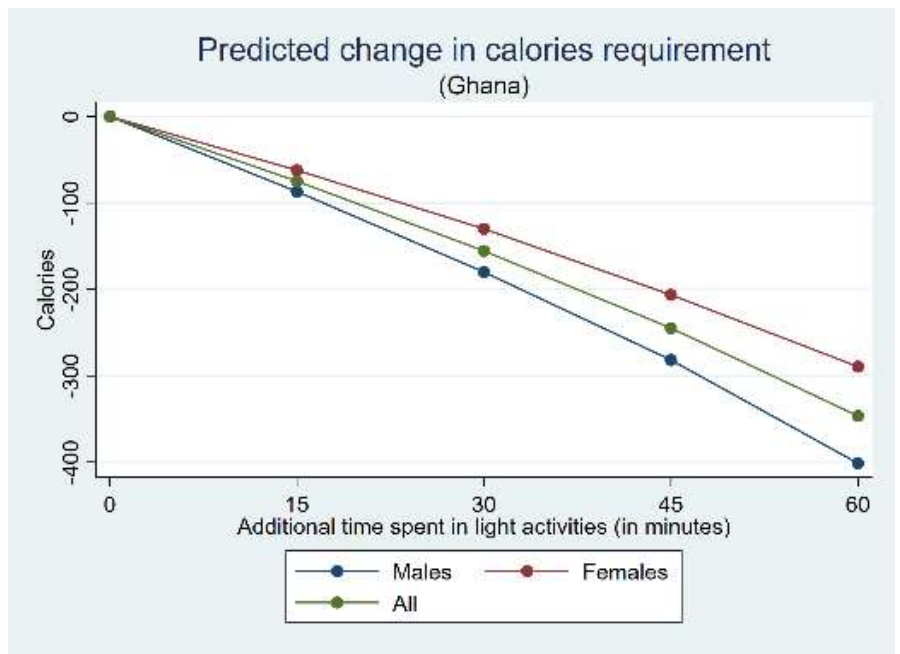

B - India



To understand the marginal effect on energy requirement of an increase in time spent in light activity, we first derive the PAL associated with a 15, 30, 45 or 60-minute increase in light activity (with a proportionate reduction in time spent in moderate and vigorous activity). The predicted PAL is then multiplied by the BMR to derive the predicted change in energy requirement. Similarly, we also derive the marginal effect on energy requirement of an increase in time spent $(15,30,45$ or 60 minutes) in moderate/vigorous activity. The mean predicted change in energy 
requirement associated with a $15,30,45$ or 60 -minute increase in the first component activity is shown in Figure-1A (Ghana) and Figure-1B (India). The predicted change in energy requirement given an increase of light activities for men and women separately is shown inFigure-2.

Figure- 1 shows that a 60 -minute increase in light activity is associated with an average reduction in calorie requirement of 350 calories/day in both Ghana and India. A 60-minute increase in moderate activity is associated with an average increase in calorie requirement of 180 calories/day in Ghana and 200 calories/day in India. A 15-minute increase in vigorous activity would be associated with an increase of 180 calories/day in Ghana and 150 calories/day in India. The fall in energy requirement associated with an increase in light activity is greater for men than women in both the countries (Figure-2) which suggests that men have larger avenues for DR than women.

\subsection{Effects of DR on calorie requirement}

We next examine how the effects of DR vary across households with different endowments and characteristics. Table-8 presents the change in calorie requirement due to DR (i.e., increase in light activity by 60 minutes with a proportionate decrease in moderate and vigorous activity) for men and women in (1) non-irrigated households versus irrigated households (2) large landholding households versus small landholding households (3) higher wealth index versus lower wealth index households and (4) high dependency ratio households versus low dependency ratio households. For landholding, wealth index and dependency ratio, households are categorised into two groups based on whether the household falls above or below the median value of landholding, wealth index and dependency ratio in the sample. respectively. 
Table-8: Effect of DR on calorie requirement for men and women (kcals/day) and \% change in TEE (in parenthesis), by household groups in Ghana and India.

\begin{tabular}{|c|c|c|c|c|c|c|}
\hline & \multicolumn{3}{|l|}{ Ghana } & \multicolumn{3}{|l|}{ India } \\
\hline & Men & Women & Diff & Men & Women & Diff \\
\hline Non-irrigated households & $\begin{array}{l}-420.97 \\
(-16 \%)\end{array}$ & $\begin{array}{l}-329.68 \\
(-13 \%)\end{array}$ & $-91.29 * * *$ & $\begin{array}{l}-459.43 \\
(-24 \%)\end{array}$ & $\begin{array}{l}-241.94 \\
(-15 \%)\end{array}$ & $-217.49^{* * *}$ \\
\hline Irrigated households & $\begin{array}{l}-306.81 \\
(-11 \%)\end{array}$ & $\begin{array}{l}-317.76 \\
(-14 \%)\end{array}$ & 10.95 & $\begin{array}{l}-418.85 \\
(-17 \%)\end{array}$ & $\begin{array}{l}-255.2 \\
(-14 \%)\end{array}$ & $-163.65^{* * *}$ \\
\hline Difference & $-114.16^{* * *}$ & -11.92 & & $-40.58 * * *$ & 13.26 & \\
\hline Bottom half wealth & $\begin{array}{l}-394.57 \\
(-14 \%)\end{array}$ & $\begin{array}{l}-305.07 \\
(-13 \%)\end{array}$ & $-89.5^{* * *}$ & $\begin{array}{l}-378.83 \\
(-19 \%)\end{array}$ & $\begin{array}{l}-232.73 \\
(-15 \%)\end{array}$ & $-146.1^{* * *}$ \\
\hline Top half wealth & $\begin{array}{l}-328.00 \\
(-13 \%)\end{array}$ & $\begin{array}{l}-341.65 \\
(-15 \%)\end{array}$ & 13.65 & $\begin{array}{l}-534.6 \\
(-23 \%)\end{array}$ & $\begin{array}{l}-265.8 \\
(-15 \%)\end{array}$ & $-268.8^{* * *}$ \\
\hline Difference & $-66.57^{* * *}$ & $36.58^{*}$ & & $155.77^{* *}$ & $33.07^{* *}$ & \\
\hline Small landowners & $\begin{array}{l}-326.96 \\
(-12 \%)\end{array}$ & $\begin{array}{l}-317.14 \\
(-13 \%)\end{array}$ & -9.82 & $\begin{array}{l}-410.86 \\
(-19 \%)\end{array}$ & $\begin{array}{l}-234.6 \\
(-14 \%)\end{array}$ & $-176.26^{* * *}$ \\
\hline Large landowners & $\begin{array}{l}-413.74 \\
(-16 \%)\end{array}$ & $\begin{array}{l}-327.15 \\
(-14 \%)\end{array}$ & $-86.59 * * *$ & $\begin{array}{l}-477.22 \\
(-22 \%)\end{array}$ & $\begin{array}{l}-298.61 \\
(-17 \%)\end{array}$ & $-178.61^{* * *}$ \\
\hline Difference & $86.78^{* *}$ & 10.01 & & $66.36^{* *}$ & $64.01^{* *}$ & \\
\hline Small dependency ratio & $\begin{array}{l}-347.38 \\
(-13 \%)\end{array}$ & $\begin{array}{l}-322.9 \\
(-14 \%)\end{array}$ & -24.48 & $\begin{array}{l}-451.55 \\
(-22 \%)\end{array}$ & $\begin{array}{l}-247.79 \\
(-15 \%)\end{array}$ & $-203.76^{* * *}$ \\
\hline Large dependency ratio & $\begin{array}{l}-421.54 \\
(-16 \%)\end{array}$ & $\begin{array}{l}-328.69 \\
(-14 \%)\end{array}$ & $-92.85^{* * *}$ & $\begin{array}{l}-458.39 \\
(-19 \%)\end{array}$ & $\begin{array}{l}-265.94 \\
(-15 \%)\end{array}$ & $-192.45^{* * *}$ \\
\hline Difference & $74.16^{* *}$ & 5.79 & & 6.84 & 18.15 & \\
\hline
\end{tabular}

5. Asterisks show level of significance ${ }^{* * *}=$ significant at $0.1 \%$ level, ${ }^{* *}=$ significant at $1 \%$ level and ${ }^{*}=$ significant at $5 \%$ level NS = Not Significant.

It should be noted that for men and women in any household category, the effects of DR on calorie requirement depend on (1) current proportions of time allocated to light, moderate and vigorous activity and (2) the relative energy intensity of moderate and vigorous activities which are substituted with light activities. The results of the compositional regressions run to assess the relative energy intensities of light, moderate and vigorous activities for men and women in different household categories are presented in Appendix Tables C and $\mathrm{D}^{3}$. In Ghana, the average reduction in calorie requirement associated with DR ranges from $11-16 \%$ of TEE for men, and from $13-15 \%$ for women. In India, the average reduction on calorie requirement for men ranges from $17-22 \%$ and $14-17 \%$ for women.

In India reduction in energy requirement of men is significantly higher than that of women for all household categories. In Ghana the reduction in energy requirement is significantly larger for men than for women in all categories except in irrigated, wealthier, small landholding and low dependency households where the differences are not significant. In Ghana the largest reductions

\footnotetext{
3 The coefficients of the compositional regression presented in Appendix Tables C and D cannot be interpreted as the energy intensity (in kcals/minute) of the light, moderate and vigorous activities. They provide only an index of the relative intensity of light, moderate and vigorous activities.
} 
in energy requirements from DR for men are found in non-irrigated households, while in India it is the wealthier households where this is the largest. For women, the largest effects of DR on energy requirements are found in wealthier households Ghana and in wealthier households and large dependency households in India. A comparison of the effects of DR in different household categories reveals the following patterns:

Size of landholding: The effects of DR are significantly different for men in small versus large landowning households, with the potential for reduction in energy requirements from DR being larger in large landholding households. The differences in the effects of DR between small and large landholding households are significant for women only in India, with women in large landholding households having a larger reduction in energy requirements from DR.

Irrigation status: There are significant differences in the effects of DR between non-irrigated and irrigated households for men. In both countries, the reduction in calorie requirement is significantly higher for men in non-irrigated households. The differences in the effects of DR between irrigated and non-irrigated households is not significant for women.

Wealth: There are significant differences the reduction in energy requirements in DR between wealthier and poorer households for both men and women. For women the effects of DR are larger in wealthier households in both countries. However, men in poorer households in Ghana have a larger reduction in energy requirements from DR, while in India it is men in wealthier households who experience a larger reduction in energy requirements.

Dependency ratio: There are no significant differences in the effects of DR between low and high dependency households, except for men in Ghana, where the reductions in energy requirements for men are significantly larger in high dependency households. 


\section{Discussion}

While our samples of rural households in Ghana and India may not be nationally representative, these case studies provide important novel insights into the changing physical activity intensity of rural livelihoods in these countries. The picture that emerges from energy expenditure profiles does not conform to the stylised depictions of "farmers toiling in the fields". The assumption of continuous intense physical activity and associated drudgery is not upheld by these empirical data. The proportion of time spent in moderate or vigorous activity is only around $15 \%$ of total time, with vigorous activity accounting for only $1-2 \%$ of total time use. This may be attributable to the introduction of mechanisation and other labour-saving technologies in agriculture and the provision of improved transportation and communication infrastructure in rural areas. However, the proportion of time spent on moderate-to-vigorous activity (approximately 3.5 hours per day) remains considerably higher than that recommended for sedentary populations in high income country settings: a typical recommendation for sedentary populations is 150 minutes of moderate-to-vigorous physical activity (MVPA) per week (Department of Health, 2011).

The average TEE in both countries is well below the normative energy requirement norms used for poverty estimations in both countries. Daily Activity Energy Expenditure (AEE) and Total Energy Expenditure (TEE) are the higher in Ghana than in India. In Ghana, the mean TEE is well below the 2900 per capita per day calorie requirement assumed in national poverty line estimations (Ghana Statistical Service, 2018). Similarly, in India, the mean TEE is below the calorie requirement norm for rural areas (2400 calories per capita per day) that underlie poverty line estimations (Government of India, 2014). The normative energy requirements used in poverty and undernutrition estimations are several decades old and may not reflect energy expenditure patterns in rural livelihoods in the present day. Assessments of poverty and calorie inadequacy made using these normative calorie requirements may run the risk of overestimating the incidence of poverty and undernutrition. 
TEE and AEE are higher for men than women in all categories of households, but the PAL for women is higher in all categories of households. Although we have not reported the PAL on an hourly basis, our data shows that women maintain a higher PAL than men over the entire course of the day. This may reflect the nature of roles allotted to men and women in rural households. The nature of activities allocated to women - cooking, childcare, fetching water and firewood and domestic chores - in addition to participation in agriculture or other economic activities- may mean that they are required to remain physically active on a sustained basis (over longer periods of time) through the course of the day, even when it is the men who undertake the high intensity physical activities.

Our results show that DR in rural livelihoods can have large impacts on energy requirements. In Ghana the substitution of one hour of moderate to vigorous activity by light activity leads to a reduction in energy requirement which can offset nearly two-thirds of the average calorie deficit faced by men and women (Table-3). In India, reduction in energy requirements from DR can offset nearly two-thirds of the average calorie deficit for men, while it can more than offset the average calorie deficit for women. This result shows that labour-saving interventions have the potential for significant impact on calorie adequacy, even without improvements in food intake. The effects of DR on nutritional status may extend beyond improved calorie adequacy. Reduced calorie requirements on account of DR can also facilitate improvements in dietary diversity and quality via an "income effect" arising from reduced expenditure on calories. These results also suggest that for certain segments of the rural population, reduction in energy requirements from DR coupled with unchanging patterns of dietary intake may lead to incidence of obesity and overweight (Bixby et al., 2019). This is consistent with the rising incidence of obesity observed in the rural populations of both India (Luhar et al., 2018) and Ghana (Oferi-Asenso et al, 2016).

The effects of DR depend on the choices for activity substitution. These choices may be influenced by individual and household characteristics and endowments. The larger effect of DR for men compared to women may reflect the differences in roles allocated to men and women in rural households and the choices that they face for substituting moderate and vigorous physical 
activity with light activity. Certain types of substitutions may be available for, or relevant to, only men. For example, if ploughing using draught animals is an activity traditionally done by men, then the introduction of mechanised ploughing may offer DR potential only for men. It is also possible that development of DR measures may be subject to gender bias - this would arise if more effort is expended in mechanising ploughing (an activity largely in men's domain) rather than mechanising paddy transplanting (an activity largely undertaken by women). Substitutions may also offer larger reductions in energy requirement for men, e.g., the substitution of mechanised ploughing for animal draught ploughing may offer larger reductions in energy requirements than a gadget that reduces the drudgery of domestic chores for women. The effect of DR also depends on whether it eliminates the need for an activity providing more time for leisure and rest or whether it substitutes a more intense activity for a less intense activity.

Our results also suggest that substitution possibilities are different across different categories of households. For men large avenues for DR are to be found in non-irrigated households. If the absence of irrigation facilities is regarded as a proxy for lack of mechanisation or adoption of improved technologies, then the large changes in energy requirement for non-irrigated households may reflect the gains due to mechanisation. This potential for reduction in energy requirement may not be available in households that are already mechanised. The avenues for DR through mechanisation may be oriented towards men, which may explain the lower energy reduction for women in non-irrigated households.

There appear to be relatively larger avenues for DR for women in larger landholding, irrigated and wealthier households. Some of the avenues for DR for women in larger landholding/irrigated/richer households may arise from varying their participation in agricultural activities (e.g., substituted by hired labour). This may not be an option available to women in small landholding households. Other avenues for DR could be related to domestic chores - e.g., energy requirement reduction through improved fuel sources, transportation, gadgets and durables - but again these options may be available only in better endowed households (i.e., larger landholding, irrigated or richer households). The dependency ratio in 
households (the presence of children, elderly or the sick who need care) and the allocation of tasks for caring for dependents also affect the potential for DR faced by women. The lack of a significant difference in the effects of DR for women in low and high dependency households suggests that women in rural households have limited avenues for reducing their workload related to care of dependants.

\section{Conclusions}

Agricultural and rural development interventions designed to address undernutrition in LMICs have tended to focus on productivity-enhancement, raising household incomes and/or increasing food intake among nutritionally-vulnerable people. While it is recognised that productivityenhancing interventions can place increased demands for physical activity and exertion on the intended beneficiaries, the energy expenditure dimension associated with such interventions is seldom accounted for when analysing the potential for nutrition impacts. The results presented here suggest that changing patterns of physical activity in rural livelihoods can have rather large impacts on calorie adequacy and on nutrition outcomes, and that such impacts are differentiated by gender, household characteristics and asset endowments. The key insight from this paper is that explicit consideration of the energy expenditure dimension can provide a better understanding of the pathways from productivity-enhancement to nutrition. This may help us better understand the links between agricultural development and nutrition outcomes observed in several LMICs. Productivity-enhancing interventions need to be assessed in terms of the impact on food intakes as well as physical activity demands that they place on beneficiaries. Our results suggest that changing the energy expenditure profile of men and women in rural households can provide an important route to nutritional improvement. There may be strong case to be made for provision of rural infrastructure on the basis of how they affect energy expenditure profiles and hence nutrition. In bringing about nutrition status improvements through changing physical activity patterns, rural households may be constrained by the limited choices that they face for activity substitution and DR. Interventions must be designed to broaden these choices. 


\section{AUTHOR STATEMENT}

C.S.Srinivasan: Conceptualization, Methodology, Formal Analysis, Writing -Original Draft, Writing- Review and Editing.

Giacomo Zanello: Supervision, Project Administration, Investigation, Conceptualization, Methodology, Software, Formal Analysis, Writing- Original Draft, Writing - Review and Editing.

Paul Nkegbe: Project Administration, Investigation, Data Curation, Writing- Review and Editing.

Radhika Cherukuri: Project Administration, Investigation, Data Curation, Writing- Review and Editing.

Fiorella Picchioni: Investigation, Data Curation, Formal Analysis,Software, Visualisation.

Nithya Gowdru: Investigation, Data Curation, Writing- Review and Editing.

Patrick Webb: Conceptualisation, Writing- Review and Editing.

\section{Acknowledgments}

This research was supported by the DFID-IMMANA Grant \#2.03 funded by UK aid from the UK Government. The views expressed do not necessarily reflect the UK Government's official policies. We are also grateful for comments from participants at Seminar at the International Food Policy Research Institute (IFPRI) and Bloomberg School of Public Health (Johns Hopkins University). Patrick Webb also acknowledges support for his contribution to this work from the Feed the Future Innovation Lab for Nutrition, which is funded by the United States Agency for International Development (USAID) under award number AIDOAA-l-10-00005 to Tufts University. 


\section{References}

Aitchison, J. (1982). The statistical analysis of compositional data. Journal of the Royal Statistical Society: Series B (Methodological) 44(2), 139-160.

Bains, K., Kaur, B. and Mann, S. K. (2002). Measurement of energy cost of selected household and farm activities performed by rural women. Food and Nutrition Bulletin 23(3), 274-279.

Barker, M., Chorghade, G., Crozier, S., Leary, S. and Fall, C. (2006). Gender differences in body mass index in rural India are determined by socio-economic factors and lifestyle. The Journal of Nutrition 136(12), 3062-3068.

Bixby, H., Bentham, J., Zhou, B. et al. (2019) Rising rural body-mass index is the main driver of the global obesity epidemic in adults. Nature 569, 260-264. (2019).

Bleiberg, F., Brun, T. A., Goihman, S., and Lippman, D. (1981). Food intake and energy expenditure of male and female farmers from Upper-Volta. British Journal of Nutrition 45, 505-515.

Bowen, L., Ebrahim, S., De Stavola, B., Ness, A., Kinra, S., Bharathi, A.V., Prabhakaran, D. and Reddy, K.S., (2011). Dietary intake and rural-urban migration in India: a cross-sectional study. PloS One 6(6), e14822.

Ceesay, S. M., Prentice, A. M., Day, K. C., Murgatroyd, P. R., Goldberg, G. R., Scott, W., and Spurr, G. (1989). The use of heart rate monitoring in the estimation of energy expenditure: a validation study using indirect whole-body calorimetry. British Journal of Nutrition 61, 175-186.

Chastin, S.F., Palarea-Albaladejo, J., Dontje, M.L. and Skelton, D.A., (2015). Combined effects of time spent in physical activity, sedentary behaviors and sleep on obesity and cardio-metabolic health markers: a novel compositional data analysis approach. PloS One 10(10), p.e0139984.

Chen, K.Y. and Bassett, D.R (Jr), (2005). The technology of accelerometry-based activity monitors: current and future. Medicine and Science in Sports \& Exercise 37(11), S490-S500.

Dangour, A. D., Hawkesworth, S., Shankar, B., Watson, L., Srinivasan, C. S., Morgan, E. H, Haddad, L. and Waage, J. (2013). Can nutrition be promoted through agriculture-led food price policies? A systematic review. BMJ Open 3(6).

Deaton, A., \& Drèze, J. (2009). Food and nutrition in India: facts and interpretations. Economic and Political Weekly XLIV, 42-65.

Department of Health. (2011). Start active, stay active: A report on physical activity for health from the four home countries' Chief Medical Officers. Department of Health, London.

Dufour, D. L., and Piperata, B. A. (2008). Energy expenditure among farmers in developing countries: what do we know? American Journal of Human Biology 20, 249-258.

Dumuid, D., Pedišić, Ž., Stanford, T.E., Martín-Fernández, J.A., Hron, K., Maher, C.A., Lewis, L.K. and Olds, T. (2019). The compositional isotemporal substitution model: A method for estimating changes in a health outcome for reallocation of time between sleep, 
physical activity and sedentary behaviour. Statistical Methods in Medical Research 28(3), 846-857.

Durnin, J., and Brockway, J. (1959). Determination of the total daily energy expenditure in man by indirect calorimetry: assessment of the accuracy of a modern technique. British Journal of Nutrition 13, 41-53.

Durnin, J.V., Drummond, S. and Satyanarayana, K., (1990). A collaborative EEC study on seasonality and marginal nutrition: the Glasgow Hyderabad (S. India) Study. European Journal of Clinical Nutrition 44, 19-29.

Edmundson, W. C., and Edmundson, S. A. (1989). Energy balance, nutrient intake and discretionary activity in a South Indian village. Ecology of Food and Nutrition 22, 253-265.

Fan, S., Yosef, S., and Pandya-Lorch, R., (eds.) (2019). Agriculture for Improved Nutrition: Seizing the Momentum. International Food Policy Research Institute/CABI International. Washington, D.C. and Wallingford, UK.

FAO (2001). Human Energy Requirements. Report of a Joint FAO/WHO/UNU Expert Consultation. Food and Nutrition Technical Report Series. Rome: FA

FAO (2011). The State of Food and Agriculture -2010-2011. Women in Agriculture Closing the gender gap for development. Food and Agriculture Organization of the United Nations, Rome.

FAO, IFAD and WFP (2015). The State of Food Insecurity in the World 2015 - Meeting the 2015 international hunger targets: taking stock of uneven progress. Rome, FAO.

Freedson, P.S., Melanson, E. and Sirard, J. (1998). Calibration of the Computer Science and Applications, Inc. accelerometer. Medicine and Science in Sports and Exercise 30(5), 777781.

Ghana Statistical Service (2018). Poverty Trends in Ghana - 2005-2017. Ghana Living Standards Survey Round 7 (GLSS 7).

Gillespie, S., Harris, J. and Kadiyala, S. (2012) The Agriculture-Nutrition Disconnect in India: What Do We Know? IFPRI Discussion Paper 01187. Washington, DC (USA).

Girard, A. W., Self, J. L., McAuliffe, C. and Olude, O. (2012). The effects of household food production strategies on the health and nutrition outcomes of women and young children: A systematic review. Paediatric and Perinatal Epidemiology 26, 205-222.

Gite, L. P., and Singh, G. (1997). Ergonomics in agricultural and allied activities in India. Technical Bulletin, Central Institute of Agricultural Engineering, India

Global Panel (2015). Improved metrics and data are needed for effective food system policies in the post-2015 era. Technical Brief. London, UK: Global Panel on Agriculture and Food Systems for Nutrition.

Government of India (2014). Report of the Expert Group to Review the Methodology for Measurement of Poverty. Planning Commission, Government of India.

Griffiths, P.L. and Bentley, M.E. (2001). The nutrition transition is underway in India. The Journal of Nutrition 131(10), 2692-2700. 
Guzman, P., de, P., MA, Dominguez, S., Kalaw, J., Basconcillo, R., and Santos, V. (1974). A study of the energy expenditure, dietary intake, and pattern of daily activity among various occupational groups. The Philippine Journal of Nutrition 113, 29-46.

Harris, J.A. and Benedict, F.G. (1918). A biometric study of human basal metabolism. Proceedings of the National Academy of Sciences of the United States of America 4(12), 370.

Headey, D., Chiu, A. and Kadiyala S. (2011). Agriculture's Role in the Indian Enigma: Help or Hindrance to the Undernutrition Crisis? Discussion Paper 01085. Washington, DC: International Food Policy Research Institute.

Heini, A., Minghelli, G., Diaz, E., Prentice, A., and Schutz, Y. (1996). Free-living energy expenditure assessed by two different methods in rural Gambian men. European Journal of Clinical Nutrition 50, 284-289.

IFAD (2016). Rural Development Report 2016: Fostering Inclusive Rural Transformation. International Fund for Agricultural Development, Rome, Italy.

IFPRI (2015). Global Nutrition Report 2015: Actions and Accountability to Advance Nutrition and Sustainable Development. Washington DC (USA): International Food Policy Research Institute.

Johnston, D., Stevano, S., Malapit, H.J., Hull, E. and Kadiyala, S., (2018). Time Use as an Explanation for the Agri-Nutrition Disconnect: Evidence from Rural Areas in Low and Middle-Income Countries. Food Policy 76, .8-18.

Keino, S., van den Borne, B. and Plasqui, G. (2014). Body composition, water turnover and physical activity among women in Narok County, Kenya. BMC Public Health 14(1), 1212.

Kishtwaria, J. and Rana, A. (2012). Ergonomic interventions in weeding operations for drudgery reduction of hill farm women of India. Work 41(Supplement 1), 4349-4355.

Luhar, S., Mallinson, P. A. C., Clarke, L., \& Kinra, S. (2018). Trends in the socioeconomic patterning of overweight/obesity in India: a repeated cross-sectional study using nationally representative data. BMJ Open 8(10), e023935.

Meeker, J., and Haddad, L. (2013). A state-of-the-art review of agriculture-nutrition linkages. An AgriDiet Position Paper. Department of Food Business and Development, University College Cork, Ireland.

Mohanty, S. K., Behera, B. K., and Satapathy, G. C. (2008). Ergonomics of farm women in manual paddy threshing. Agricultural Engineering International: CIGR Journal.

Murayama, N., and Ohtsuka, R. (1999). Seasonal fluctuation in energy balance among farmers in Northeast Thailand: the lack of response of energy intake to the change of energy expenditure. European Journal of Clinical Nutrition 53, 39-49.

Nag, P. K., and Nag, A. (2004). Drudgery, accidents and injuries in Indian agriculture. Industrial Health 42(2), 149-162.

Nag, P. K., Sebastian, N. C. and Mavlankar, M. G. (1980). Occupational workload of Indian agricultural workers. Ergonomics 23(2), 91-102.

Norgan, N. (1996). Measurement and interpretation issues in laboratory and field studies of energy expenditure. American Journal of Human Biology 8, 143-158. 
Ofori-Asenso, R., Agyeman, A. A., Laar, A., \& Boateng, D. (2016). Overweight and obesity epidemic in Ghana - a systematic review and meta-analysis. BMC Public Health 16(1), 1239.

Pasquet, P., \& Koppert, G. J. (1993). Activity Patterns and Energy Expenditure in Cameroonian Tropical Forest Populations. MAN AND THE BIOSPHERE SERIES, 13, 311 311.

Pawlowski, C.S., Andersen, H.B., Troelsen, J. and Schipperijn, J., (2016). Children's physical activity behavior during school recess: A pilot study using GPS, accelerometer, participant observation, and go-along interview. PloS One 11(2), e0148786.

Rao, S., Gokhale, M. and Kanade, A., (2008). Energy costs of daily activities for women in rural India. Public Health Nutrition 11(2), 142-150.

Ruel, M. T., Alderman, H. and Maternal and Child Nutrition Study Group. (2013). Nutritionsensitive interventions and programmes: how can they help to accelerate progress in improving maternal and child nutrition? The Lancet 382(9891), 536-551.

Santos-Lozano, A., Santín-Medeiros, F., Cardon, G., Torres-Luque, G., Bailón, R., Bergmeir, C., Ruiz, J., Lucia, A., and Garatachea, N. (2013). Actigraph GT3X: Validation and Determination of Physical Activity Intensity Cut Points. International Journal of Sports Medicine 34, 975-982.

Sasaki, J.E., John, D. and Freedson, P.S. (2011). Validation and comparison of ActiGraph activity monitors. Journal of Science and Medicine in Sport 14(5), 411-416.

Singh, S. P., Gite, L. P., Agarwal, N. and Majumder, J. (2007). Women friendly improved farm tools and equipment. Technical Bulletin No. CIAE/2007/128. Bhopal: Central Institute of Agricultural Engineering (CIAE).

Speakman, J. R. (1998). The history and theory of the doubly labeled water technique. The American Journal of Clinical Nutrition 68(4), 932S-938S.

Turner, R., Hawkes, C., Waage, J., Ferguson, E., Haseen, F., Homans, H., Hussein, J., Johnston, D., Marais, D., McNeill, G., and Shankar, B. (2013). Agriculture for improved nutrition: The current research landscape. Food and Nutrition Bulletin 34(4), 369-377.

Vaz, M., Karaolis, N., Draper, A., and Shetty, P. (2005). A compilation of energy costs of physical activities. Public Health Nutrition 8, 1153-1183.

Vinoy, S., Rosetta, L., and Mascie-Taylor, C. (2000). Repeated measurements of energy intake, energy expenditure and energy balance in lactating Bangladeshi mothers. European Journal of Clinical Nutrition 54, 579-585.

von Grebmer, K., Bernstein, J., de Waal, A., Prasai, N., Yin, S. \& Yohannes, Y. (2015). 2015 Global hunger index: Armed conflict and the challenge of hunger. Bonn, Germany; Washington, D.C. and Dublin, Ireland: Welthungerhilfe; International Food Policy Research Institute (IFPRI) and Concern Worldwide.

Webb, P. and Block, S. (2012) Support for agriculture during economic transformation: Impacts on poverty and undernutrition. Proceedings of the National Academies of Science 109 (31), 12309-12314.

Webb, P. and Kennedy, E. (2014). Impacts of agriculture on nutrition: nature of the evidence and research gaps. Food and Nutrition Bulletin 35(1), 126-132. 
Zanello, G., Srinivasan, C.S. and Nkegbe, P. (2017). Piloting the use of accelerometry devices to capture energy expenditure in agricultural and rural livelihoods: Protocols and findings from northern Ghana. Development Engineering 2, 114-131.

Zanello, G., Srinivasan, C. S., Picchioni, F., Webb, P., Nkegbe, P., Cherukuri, R., Neupane, S., Ustarz, Y., Gowdru, N., Neupane, S., and Wyatt, A. J. (2018). Using Accelerometers in Low- and Middle-Income Countries: A Field Manual for Practitioners. University of Reading. Reading (UK).

Zanello, G., Srinivasan, C., Picchioni, F., Webb, P., Cherukuri, R., Nkegbe, P., \& Neupane, S. (2019). Physical activity, time use, and food intakes of rural households in Ghana, India, and Nepal 2017-2018 [dataset]. Colchester, Essex (UK): UK Data Service. 


\section{Appendix}

\section{Variable definitions in compositional regression equations}

Isometric log ratio (ilr) variables: In all the compositional regressions results shown in the following tables, the ilr variables are the isometric log ratio transformations of the compositional explanatory variables, i.e., the number of minutes spent in light, moderate and vigorous activities during the day. The ilr variables are defined as follows:

$$
\begin{aligned}
\text { ilr-Light Activity } & \left.=\sqrt{\frac{2}{3}} \ln \left(\frac{L A}{\sqrt{M A X V A}}\right)\right) \\
\text { ilr2- Light Activity } & =\sqrt{\frac{1}{2}} \ln \left(\frac{M A}{V A}\right) \\
\text { ilr-Moderate Activity } & =\sqrt{\frac{2}{3}} \ln \left(\frac{M A}{\sqrt{L A X V A}}\right) \\
\text { ilr2-Moderate Activity } & =\sqrt{\frac{1}{2}} \ln \left(\frac{L A}{V A}\right) \\
\text { ilr-Vigorous Activity } & =\sqrt{\frac{2}{3}} \ln \left(\frac{V A}{\sqrt{L A X M A}}\right) \\
\text { ilr2-Vigorous Activity } & =\sqrt{\frac{1}{2}} \ln \left(\frac{L A}{M A}\right)
\end{aligned}
$$

\begin{tabular}{|c|c|}
\hline \multirow{2}{*}{\multicolumn{2}{|c|}{ In all the compositional regressions in Tables A, and B, the covariates are as follows: }} \\
\hline & \\
\hline Sex & Gender of the respondent (dummy variable - female $=1$, male $=0$ ) \\
\hline Health status & Whether respondent's ability to work has been affected by health isst \\
\hline Total land & Land owned by household in hectares \\
\hline Wealth index & $\begin{array}{l}\text { Index of wealth calculated from ownership of different types of ass } \\
\text { Principal Components Analysis following the procedure in Filmer anc }\end{array}$ \\
\hline Tropical Livestock Unit & $\begin{array}{l}\text { Tropical Livestock Units are livestock numbers converted to a comm } \\
\text { factors are: cattle }=0.7 \text {, sheep }=0.1 \text {, goats }=0.1 \text {, pigs }=0.2 \text {, chicken }=0\end{array}$ \\
\hline Irrigation & Irrigation $=$ Whether agricultural land is irrigated (dummy variable) \\
\hline Number of elderly & Number of household members aged $>64$ years \\
\hline Number of adults & Number of household members aged $>18$ years \\
\hline Number of adolescents & Number of household members aged $12-18$ years \\
\hline Number of children & Number of household members aged 4-12 years \\
\hline Number of infants & Number of children in the household aged $0-4$ years \\
\hline
\end{tabular}

where LA = number of minutes spent in a day in light activity, MA = number of minutes in a day spent in moderate activity and VA $=$ number of minutes in a day spent in vigorous activity. $\mathrm{LA}+\mathrm{MA}+\mathrm{VA}=1440$

4 Filmer, D., \& Pritchett, L. H. (2001). Estimating wealth effects without expenditure data-or tears: an application to educational enrollments in states of India. Demography, 38(1), 115-132.

5 HarvestChoice, 2015. "Tropical Livestock Units (TLU, 2005)." International Food Policy Research Institute, Washington, DC and University of Minnesota, St. Paul, MN. Available online at http://harvestchoice.org/data/an05_tlu 
Missing hours

Day 1-6

Seeding and sowing; Land maintenance; Harvest
Dummy variable indicating whether there were periods of the accelerometer not being worn during waking hours. Note: Observations for only those days were included in the analysis where the period of non-wear during waking hours was less than 3 hours.

Consecutive observation days during which accelerometers were worn by respondents

Dummy variables indicating the phase of the agricultural season during which the respondents were observed.

Note that the co-efficients of all the covariates are the same in all the three regressions, i.e., when the first compositional variable is taken by turn to be the minutes spent in light activity, minutes spent in moderate activity and minutes spent in vigorous activity. 
Table A: Compositional regression models of Physical Activity Level (PAL) in Ghana

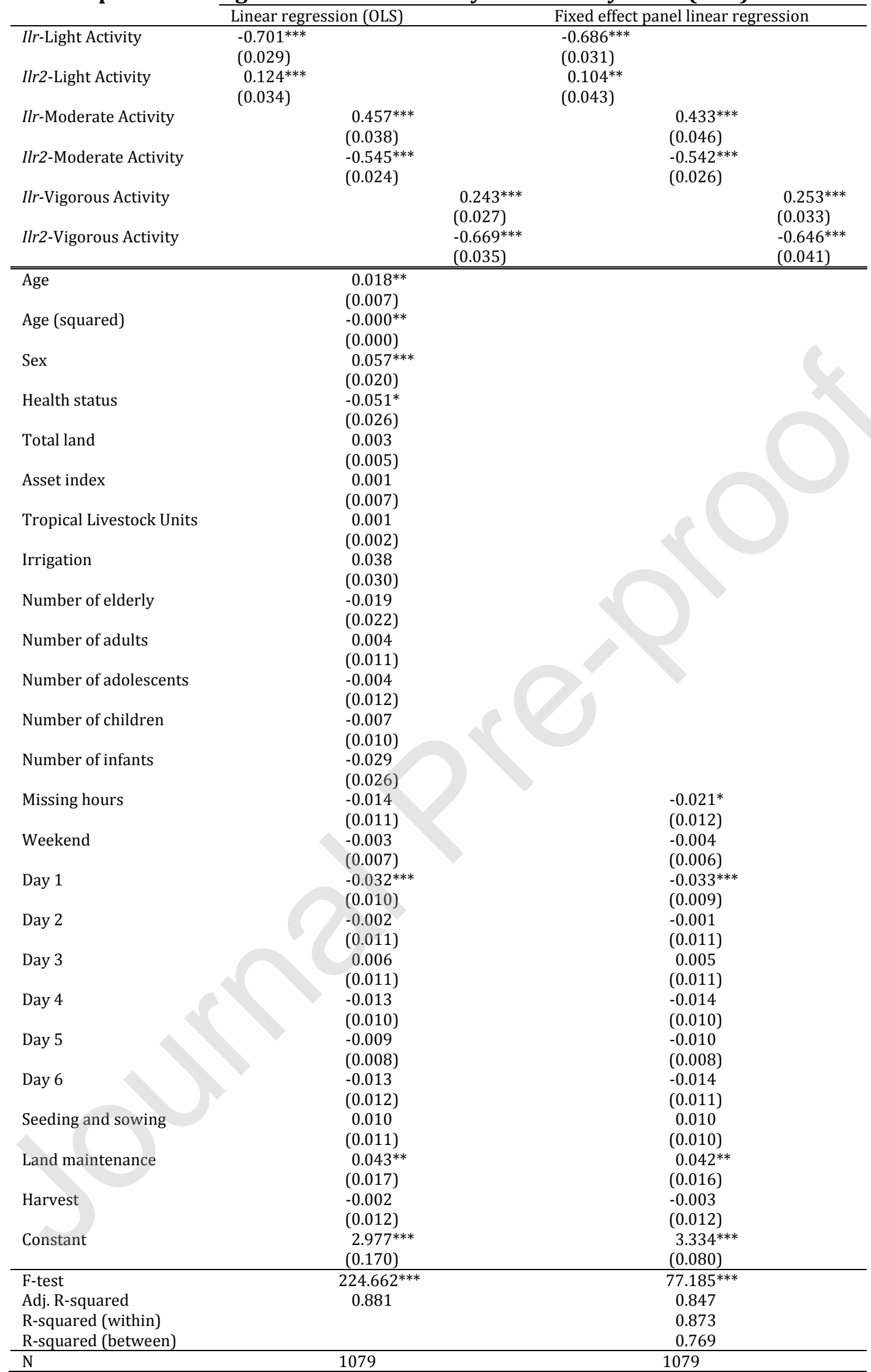

6. Asterisks show level of significance ${ }^{* * *}=$ significant at $1 \%$ level, ${ }^{* *}=$ significant at $5 \%$ level and ${ }^{*}=$ significant at $10 \%$ level. In the linear regression (OLS), standard errors clustered at household level. Robust standard errors in the fixed effects linear regression. 
Table B: Compositional regression models of Physical Activity Level (PAL) in India



7. Note: Asterisks show level of significance ${ }^{* * *}=$ significant at $1 \%$ level, ${ }^{* *}=$ significant at $5 \%$ level and *=significant at $10 \%$ level. In the linear regression (OLS), standard errors clustered at household level. Robust standard errors in the fixed effects linear regression 
Table C: Compositional regressions for estimation of relative energy intensities of light, moderate and vigorous activities (Ghana)

\begin{tabular}{|c|c|c|c|c|c|c|c|c|c|c|c|c|c|c|c|c|}
\hline & \multicolumn{4}{|c|}{ Agricultural system } & \multicolumn{4}{|l|}{ Wealth } & \multicolumn{4}{|c|}{ Land ownership } & \multicolumn{4}{|c|}{ Dependency ratio } \\
\hline & \multicolumn{2}{|l|}{ Rainfed } & \multicolumn{2}{|l|}{ Irrigated } & \multicolumn{2}{|l|}{ Bottom half } & \multicolumn{2}{|l|}{ Top half } & \multicolumn{2}{|c|}{ Small } & \multicolumn{2}{|l|}{ Large } & \multicolumn{2}{|l|}{ Small } & \multicolumn{2}{|l|}{ Large } \\
\hline & Men & Women & Men & Women & Men & Women & Men & Women & Men & Women & Men & Women & Men & Women & Men & Women \\
\hline Light & $\begin{array}{c}-31.074^{* * *} \\
(0.390)\end{array}$ & $\begin{array}{l}-28.132^{* * *} \\
(1.012)\end{array}$ & $\begin{array}{l}-27.964^{* * *} \\
(1.063)\end{array}$ & $\begin{array}{l}-22.495 * * * \\
(1.176)\end{array}$ & $\begin{array}{l}-30.103^{* * *} \\
(0.648)\end{array}$ & $\begin{array}{l}-25.555^{* * *} \\
(1.810)\end{array}$ & $\begin{array}{l}-28.376^{* * *} \\
(1.355)\end{array}$ & $\begin{array}{l}-24.373 * * * \\
(1.027)\end{array}$ & $\begin{array}{l}-28.095 * * * \\
(1.024)\end{array}$ & $\begin{array}{l}-25.019^{* * *} \\
(1.212)\end{array}$ & $\begin{array}{l}-31.215 * * * \\
(0.335)\end{array}$ & $\begin{array}{l}-24.906 * * * \\
(1.846)\end{array}$ & $\begin{array}{l}-29.343^{* * *} \\
(0.933)\end{array}$ & $\begin{array}{l}-24.690 * * * \\
(1.513)\end{array}$ & $\begin{array}{l}-29.407^{* * *} \\
(1.325)\end{array}$ & $\begin{array}{l}-25.471 * * * \\
(0.889)\end{array}$ \\
\hline Moderate & $\begin{array}{l}31.018^{* * *} \\
(0.424)\end{array}$ & $\begin{array}{l}26.944^{* * *} \\
(0.911)\end{array}$ & $\begin{array}{l}27.002^{* * *} \\
(1.168)\end{array}$ & $\begin{array}{l}22.086^{* * *} \\
(1.147)\end{array}$ & $\begin{array}{l}29.899^{* * *} \\
(0.791)\end{array}$ & $\begin{array}{l}24.692^{* * *} \\
(1.592)\end{array}$ & $\begin{array}{l}27.528^{* * *} \\
(1.487)\end{array}$ & $\begin{array}{l}23.991^{* * *} \\
(0.999)\end{array}$ & $\begin{array}{l}27.224^{* * *} \\
(1.125)\end{array}$ & $\begin{array}{l}24.576^{* * *} \\
(1.197)\end{array}$ & $\begin{array}{l}31.141^{* * *} \\
(0.400)\end{array}$ & $\begin{array}{l}24.145^{* * *} \\
(1.615)\end{array}$ & $\begin{array}{l}28.660^{* * *} \\
(1.053)\end{array}$ & $\begin{array}{l}24.196^{* * *} \\
(1.422)\end{array}$ & $\begin{array}{l}29.069^{* * *} \\
(1.516)\end{array}$ & $\begin{array}{l}24.796^{* * *} \\
(0.756)\end{array}$ \\
\hline Vigorous & $\begin{array}{c}0.056 \\
(0.219)\end{array}$ & $\begin{array}{l}1.188^{*} \\
(0.587)\end{array}$ & $\begin{array}{l}0.962 * * * \\
(0.223)\end{array}$ & $\begin{array}{l}0.409 * * \\
(0.163)\end{array}$ & $\begin{array}{l}0.204 \\
(0.259)\end{array}$ & $\begin{array}{l}0.864^{* *} \\
(0.374)\end{array}$ & $\begin{array}{l}0.848^{* * *} \\
(0.224)\end{array}$ & $\begin{array}{l}0.383 \\
(0.221)\end{array}$ & $\begin{array}{l}0.871 * * * \\
(0.226)\end{array}$ & $\begin{array}{l}0.443 \\
(0.249)\end{array}$ & $\begin{array}{l}0.074 \\
(0.232)\end{array}$ & $\begin{array}{l}0.761^{* *} \\
(0.317)\end{array}$ & $\begin{array}{l}0.683^{* *} \\
(0.276)\end{array}$ & $\begin{array}{l}0.494 \\
(0.293)\end{array}$ & $\begin{array}{l}0.338 \\
(0.285)\end{array}$ & $\begin{array}{l}0.676^{* *} \\
(0.237)\end{array}$ \\
\hline Constant & $\begin{array}{c}106.300^{* * *} \\
(0.893) \\
\end{array}$ & $\begin{array}{l}99.395 * * * \\
(2.277) \\
\end{array}$ & $\begin{array}{l}103.939^{* * *} \\
(1.867)\end{array}$ & $\begin{array}{l}87.047 * * * \\
(2.297) \\
\end{array}$ & $\begin{array}{l}106.431^{* * *} \\
(1.108)\end{array}$ & $\begin{array}{l}93.644^{* * *} \\
(3.498)\end{array}$ & $\begin{array}{l}102.709 * * * \\
(2.323)\end{array}$ & $\begin{array}{l}91.723^{* * *} \\
(2.023)\end{array}$ & $\begin{array}{l}102.584^{* * *} \\
(1.829)\end{array}$ & $\begin{array}{l}93.880^{* * *} \\
(2.263) \\
\end{array}$ & $\begin{array}{l}108.069^{* * *} \\
(0.789)\end{array}$ & $\begin{array}{l}91.080^{* * *} \\
(3.639)\end{array}$ & $\begin{array}{l}105.181^{* * *} \\
(1.648)\end{array}$ & $\begin{array}{l}91.695^{* * *} \\
(2.881)\end{array}$ & $\begin{array}{l}104.518^{* * *} \\
(2.186)\end{array}$ & $\begin{array}{l}94.185 * * * \\
(1.869)\end{array}$ \\
\hline Sample & 3822 & 3618 & 3713 & 3367 & 4027 & 3839 & 3508 & 3146 & 4234 & 3869 & 3301 & 3116 & 4712 & 4501 & 2823 & 2484 \\
\hline F-test & $3223.23^{* * *}$ & $457.038^{* * *}$ & $471.043 * * *$ & $185.578^{* * *}$ & $1318.44^{* * *}$ & $141.127 * * *$ & $376.720^{* * *}$ & $289.104 * * *$ & $484.742 * * *$ & $214.404 * * *$ & $4355.85 * * *$ & $168.149 * * *$ & $579.186 * * *$ & $146.872^{* * *}$ & $421.344^{* * *}$ & $628.971^{* * *}$ \\
\hline R-squared & 0.776 & 0.759 & 0.762 & 0.737 & 0.777 & 0.749 & 0.754 & 0.729 & 0.761 & 0.739 & 0.778 & 0.741 & 0.767 & 0.735 & 0.763 & 0.749 \\
\hline
\end{tabular}

Table D: Compositional regressions for estimation of relative energy intensities of light, moderate and vigorous activities (India)

\begin{tabular}{|c|c|c|c|c|c|c|c|c|c|c|c|c|c|c|c|c|}
\hline & \multicolumn{4}{|c|}{ Agricultural system } & \multicolumn{4}{|c|}{ Wealth } & \multicolumn{4}{|c|}{ Land ownership } & \multicolumn{4}{|c|}{ Dependency ratio } \\
\hline & \multicolumn{2}{|l|}{ Rainfed } & \multicolumn{2}{|l|}{ Irrigated } & \multicolumn{2}{|c|}{ Bottom half } & \multicolumn{2}{|l|}{ Top half } & \multicolumn{2}{|l|}{ Small } & \multicolumn{2}{|l|}{ Large } & \multicolumn{2}{|l|}{ Small } & \multicolumn{2}{|l|}{ Large } \\
\hline & Men & Women & Men & Women & Men & Women & Men & Women & Men & Women & Men & Women & Men & Women & Men & Women \\
\hline Light & $\begin{array}{l}-21.857^{* * *} \\
(1.777)\end{array}$ & $\begin{array}{l}-19.591 * * * \\
(0.781)\end{array}$ & $\begin{array}{l}-29.961^{* * *} \\
(1.611)\end{array}$ & $\begin{array}{l}-22.364^{* * *} \\
(1.365)\end{array}$ & $\begin{array}{l}-23.741^{* * *} \\
(2.349)\end{array}$ & $\begin{array}{l}-20.841^{* * *} \\
(0.928)\end{array}$ & $\begin{array}{l}-27.259^{* * *} \\
(1.648)\end{array}$ & $\begin{array}{l}-20.892^{* * *} \\
(1.268)\end{array}$ & $\begin{array}{l}-22.345^{* * *} \\
(2.257)\end{array}$ & $\begin{array}{l}-19.592^{* * *} \\
(0.770)\end{array}$ & $\begin{array}{l}-28.641^{* * *} \\
(1.312)\end{array}$ & $\begin{array}{l}-22.604^{* * *} \\
(1.311)\end{array}$ & $\begin{array}{l}-23.602^{* * *} \\
(1.823)\end{array}$ & $\begin{array}{l}-20.246^{* * *} \\
(0.896)\end{array}$ & $\begin{array}{l}-27.766^{* * *} \\
(2.102)\end{array}$ & $\begin{array}{l}-21.707^{* * *} \\
(1.407)\end{array}$ \\
\hline Moderate & $\begin{array}{l}21.756^{* * *} \\
(1.784)\end{array}$ & $\begin{array}{l}19.423^{* * *} \\
(0.796)\end{array}$ & $\begin{array}{l}29.371^{* * *} \\
(1.507)\end{array}$ & $\begin{array}{l}21.907^{* * *} \\
(1.280)\end{array}$ & $\begin{array}{l}23.606 * * * \\
(2.355)\end{array}$ & $\begin{array}{l}20.629^{* * *} \\
(0.960)\end{array}$ & $\begin{array}{l}26.815^{* * *} \\
(1.519)\end{array}$ & $\begin{array}{l}20.634^{* * *} \\
(1.204)\end{array}$ & $\begin{array}{l}22.185^{* * *} \\
(2.250)\end{array}$ & $\begin{array}{l}19.381^{* * *} \\
(0.763)\end{array}$ & $\begin{array}{l}28.227^{* * *} \\
(1.253)\end{array}$ & $\begin{array}{l}22.307^{* * *} \\
(1.275)\end{array}$ & $\begin{array}{l}23.376^{* * *} \\
(1.799)\end{array}$ & $\begin{array}{l}20.006^{* * *} \\
(0.896)\end{array}$ & $\begin{array}{l}27.690^{* * *} \\
(1.908)\end{array}$ & $\begin{array}{l}21.480^{* * *} \\
(1.339)\end{array}$ \\
\hline Vigorous & $\begin{array}{l}0.101 \\
(0.076)\end{array}$ & $\begin{array}{l}0.168^{* *} \\
(0.065)\end{array}$ & $\begin{array}{l}0.590^{* *} \\
(0.257)\end{array}$ & $\begin{array}{l}0.456 \\
(0.322)\end{array}$ & $\begin{array}{l}0.135 \\
(0.096)\end{array}$ & $\begin{array}{l}0.212^{* *} \\
(0.084)\end{array}$ & $\begin{array}{l}0.445^{* *} \\
(0.191)\end{array}$ & $\begin{array}{l}0.258^{*} \\
(0.136)\end{array}$ & $\begin{array}{l}0.160 \\
(0.091)\end{array}$ & $\begin{array}{l}0.210^{* *} \\
(0.079)\end{array}$ & $\begin{array}{l}0.414^{* *} \\
(0.167)\end{array}$ & $\begin{array}{l}0.298^{*} \\
(0.152)\end{array}$ & $\begin{array}{l}0.226 * * * \\
(0.066)\end{array}$ & $\begin{array}{l}0.240^{* *} \\
(0.076)\end{array}$ & $\begin{array}{l}0.076 \\
(0.250)\end{array}$ & $\begin{array}{l}0.227 \\
(0.196)\end{array}$ \\
\hline Constant & $\begin{array}{l}82.211^{* * *} \\
(4.096)\end{array}$ & $\begin{array}{l}67.975^{* * *} \\
(1.458)\end{array}$ & $\begin{array}{l}99.654^{* * *} \\
(3.008)\end{array}$ & $\begin{array}{l}75.718^{* * *} \\
(2.532)\end{array}$ & $\begin{array}{l}85.324^{* * *} \\
(4.828)\end{array}$ & $\begin{array}{l}69.111^{* * *} \\
(1.584)\end{array}$ & $\begin{array}{l}97.258^{* * *} \\
(3.559)\end{array}$ & $\begin{array}{l}74.484^{* * *} \\
(2.437)\end{array}$ & $\begin{array}{l}81.373^{* * *} \\
(4.814)\end{array}$ & $\begin{array}{l}67.658^{* * *} \\
(1.472)\end{array}$ & $\begin{array}{l}100.901 * * * \\
(2.662) \\
\end{array}$ & $\begin{array}{l}76.512^{* * *} \\
(2.319)\end{array}$ & $\begin{array}{l}86.783^{* * *} \\
(3.950)\end{array}$ & $\begin{array}{l}70.764^{* * *} \\
(1.698)\end{array}$ & $\begin{array}{l}95.532^{* * *} \\
(4.357)\end{array}$ & $\begin{array}{l}72.754^{* * *} \\
(2.521)\end{array}$ \\
\hline F-test & 78.193 & 343.034 & 199.913 & 147.068 & 52.751 & 311.542 & 222.596 & 164.010 & 49.404 & 323.911 & 263.184 & 153.640 & 85.209 & 258.543 & 231.656 & 134.780 \\
\hline R-squared & 0.690 & 0.732 & 0.726 & 0.711 & 0.684 & 0.734 & 0.708 & 0.702 & 0.661 & 0.741 & 0.735 & 0.702 & 0.677 & 0.719 & 0.719 & 0.717 \\
\hline
\end{tabular}

Notes: The above compositional regressions had Activity Energy Expenditure (AEE) as the dependent variable and the (ilr transformed) minutes in each hour (summing to 60 minutes) spent on light, moderate and vigorous activity as the explanatory variables. Three sets of regression were run separately for men and women in each household category:

1. AEE as dependent variable and minutes in light activity as the first compositional variable.

2. AEE as dependent variable and minutes in moderate activity as the first compositional variable.

3. AEE as dependent variable and minutes in vigorous activity as the first compositional variable.

The coefficients reported above are the coefficients of the first compositional variable from each of the three sets of regressions. The coefficients show, for example, that the energy intensity of moderate activities for men is greater in irrigated households (coefficient value $=29.371$ ) than in non-irrigated households (co-efficient value=21.756). Note that these coefficients from compositional regressions cannot be interpreted as the energy intensity (in kcals/minute) of light, moderate and vigorous activities. 